\title{
Dimension Accessibility as a Predictor of Morphological Gradability
}

\author{
Galit W. Sassoon
}

\begin{abstract}
Existing formal theories represent the interpretations of gradable predicates in terms of single scalar dimensions. This paper presents a new approach, which aims to cover morphological gradability in multidimensional adjectives and nouns. Following psychological theories, nouns are assumed to be associated with dimension sets, like adjectives. Degree constructions are proposed to involve quantification on dimensions. This approach correlates the acceptability of a given noun or adjective in comparison constructions with its type of characteristic categorization criterion (i.e., whether, as a default, its dimensions combine into a single criterion via quantifiers or other operations). A preliminary study confirms the predicted correlation. Directions for future research are proposed.
\end{abstract}

\section{Adjectives Versus Nouns in Comparison Constructions}

\subsection{The Challenges}

In model-theoretic referential semantics, the interpretation of a predicate (a word like dog, big, or card game) is modeled through its intension, namely, a function from contexts (such as worlds, times, or information states) into classes of entities, contextually given extensions. By contrast, in cognitive psychology, concepts such as 'dog', 'big', or 'card game' are modeled through their dimensions, prototypes, and similarity structures. Gradually, it has been understood that both formal and conceptual representations play a role in natural language semantics. This is evident in the study of morphological gradability, which is the topic of the present study.

Natural language predicates can be divided into various syntactic categories, two of which are adjectives and nouns. Most adjectives, including, tall, expensive and healthy among others, are morphologically gradable. In other words, they felicitously

\footnotetext{
G.W. Sassoon ( $\square)$

Department of English Literature and Linguistics, Bar Ilan University, Ramat Gan, Israel e-mail: galitadar@gmail.com 
combine with degree morphemes, as in taller, tallest, too tall, tall enough and very tall. However, some adjectives exist that are not morphologically gradable, including, for instance, geological, prime, and even. Thus, a map can be said to be more expensive than another map, but not more geological.

Degree morphemes that classically combine with gradable adjectives are, by and large, incompatible with nouns, as the infelicitous forms in (1) illustrate. The situation persists across languages (Baker 2003) In particular, within-noun comparisons such as (2) are not naturally used to compare, e.g., real ducks. Their status improves only when, e.g., toys or drawings of ducks are discussed, namely in non-literal interpretations of duck ('duck-like'). In English, when the noun occurs as the complement of a mediating particle, such as the preposition of in (3a), this also raises the acceptability of the within-noun comparison. Moreover, given nouns like duck as inputs, morpho-syntactic processes may yield adjective phrases as outputs, such as duckish or duck-like, which are compatible with degree morphemes, as illustrated in (3b).

(1) \#Ducker, \#Duckest, \#duck enough, \#too duck, \#very duck

(2) \#The rightmost bird is more a duck than the leftmost bird.

(3) a. The rightmost bird is more of a duck than the leftmost bird.

b. This toy bird is more \{duckish, duck-like\} than that toy bird.

Hence nouns are generally thought to be incompatible with degree morphemes. While the data can be explained by stipulating a syntactic constraint along these lines, researchers of gradability explain the data by postulating a semantic type difference. Nouns are conventionally thought to denote, in each context of evaluation, sets of entities, whereas adjectives are often thought to denote a scalar dimension. For example, in every world, long denotes a function, $\mathrm{f}_{\text {long }}$, from entities to their degrees on the length dimension. Non gradable adjectives are represented in terms of binary dimensions (Kennedy 1999; see von Stechow 1984 and Heim 2000 for slightly more complex degree-based types). Dimensions form the basis for categorization, therefore entities whose length exceeds a contextual membership norm are classified as long.

The problem with the syntactic-category and/or semantic-type approach comes from gradable constructions that ARE acceptable with nouns. The unacceptable construction in (2) above is a within-predicate comparison, namely, a comparison of two entities along the dimensions of a single predicate (duck). However, the between-predicate comparisons in (4a) and (5a, b), which involve comparisons of single entities along the dimensions of two different predicates, seem to have different distributional constraints. Many dimensional adjective pairs cannot naturally co-occur in such comparisons, as illustrated in (4b) (Kennedy 1999), while between-noun comparisons, such as $(5 \mathrm{a}, \mathrm{b})$, appear generally natural-clearly more than their within-noun counterparts in $(5 \mathrm{c}, \mathrm{d})$. A mediating particle of is mandatory for the latter to sound natural. 
(4) a. This dish is more sour than sweet

b. \#The table is \{longer, more long $\}$ than heavy

(5) a. Rubinstein is more a pianist than a conductor.

b. This creature is more a crab than a lobster.

c. \#Rubinstein is more a pianist than my son

d. \#This creature is more a crab than that one is.

Between-noun comparisons are often analyzed in metalinguistic terms. For example, Morzycki (2011) describes them as comparisons along degrees of imprecision of propositions in the sense of Lasershon (1999). Following this analysis, (5a) conveys that the proposition Rubinstein is a pianist is closer to the truth than the proposition Rubinstein is a conductor. A problem that arises from this analysis is that both of these propositions are plainly true. Thus, in order to explain examples like (5a), Morzycki's imprecision scale has to include various degrees of plain truth. The basis for the distinction between these degrees seems to lie in the prototypicality structures underlying categorization under pianist and conductor, but the details of this intuition have yet to be explicated (relevantly, see Hampton 2007 for the view that similarity to a prototype is a common basis for both typicality and graded membership).

In addition, Morzycki (2011) convincingly criticizes previous analyses on the grounds that they are not restrictive enough. However, his account is also not restrictive enough. (5d) is judged less natural than (5b) despite the fact that the propositions This is a crab and That is a crab may differ in terms of their distance from the truth just as much as the propositions This is a crab and This is a lobster may. Nor is the data in (1)-(2) explained, e.g., why can't degree morphemes such as very and too combine with nouns and relate to imprecision-based scales? In sum, metalinguistic scales of imprecision (or of speakers' preference, cf. Giannakidou and Yoon 2011) do not form an exhaustive account of gradability in nouns. This paper proposes that these scales emerge as a consequence of the workings of categorization mechanisms. Only the latter have the potential to explain the complexity of the data.

The goals of this paper are programmatic. It aims to give a direction for an explanation of morphological gradability and to begin developing methods to test its predictions, rather than to report some complete results. The goal is to assess more systematically the relative acceptability of nouns in different comparison types, and to begin testing additional, more specific, predictions of the hypothesized account, while indicating the issues which are left open for future research.

Multiple factors may affect judgments of acceptability, including, for example, syntactic well-formedness, adherence to a language norm or register, frequency of use, and semantic-pragmatic appropriateness (Bard et al. 1996). Focusing on semantic-pragmatic aspects, this paper explores the proposal that the role of their dimensions in categorization is an important factor in explaining the status of predicates in degree constructions. Classification under long is merely a matter of length, but classification under healthy, for example, is a matter of degree in a 
variety of dimensions such as blood-pressure, cholesterol and blood-sugar level. One can be healthy in some respects but not others (Kamp 1975; Klein 1980). Hence, in addition to the fact that, in each context, predicates denote degree functions and are associated with entity sets through classification norms (Kennedy 1999), I propose that the relation dimension of associates each predicate (e.g., bird, healthy, similar), in each context, with a set of one or more predicates-its contextual dimensions (e.g., has a beak, healthy with respect to the $\left.f u,{ }^{\prime}\right)^{1}$

While degree functions and entity sets can be learnt independently of a specification of dimensions, speakers do seem to make pervasive use of dimensions in decisions about degrees and categorization. For example, as explained in Sect. 1.2, the degree functions of nouns are often determined using the degree functions of their dimensions (functions from entities into the degree to which their values in the dimensions match certain ideal values).

Previous formal accounts have considered comparison constructions from the perspective of one-dimensional adjectives such as long. However, the naturalness of comparison constructions with multidimensional adjectives, and even with nouns, suggests that the comparison morpheme denotes an operation that can access their dimension set and use it for comparison. An important question arises concerning semantic composition. How do the different dimensions of a predicate and the operation denoted by a degree morpheme combine?

The following paraphrases of hypothesized readings of comparison constructions illustrate the potential relevance of dimensions and the way they combine together. Examples (6a) and (6b) include paraphrases for within-adjective comparisons with a dimensional and a multidimensional adjective, respectively. Examples (6c) and (6d) include possible paraphrases for between-predicate comparisons with multidimensional adjectives and nouns, respectively. A more systematic study is needed to determine whether such readings do indeed exist.

(6) a. The sofa is $2 \mathrm{~cm}$ longer than the table (is): The difference between the degree of the sofa and the table in the dimension underlying entity classification as long or not, $\mathrm{f}_{\text {length }}$, equals twice the degree of a centimeter.

b. (Generally) John is healthier than Bill: (Generally), the difference between the degrees of John and Bill in the dimensions contextually underlying entity classification as healthy or not, $\mathrm{f}_{\text {blood pressure }}, \mathrm{f}_{\text {cholesterol }}, \mathrm{f}_{\text {chickenpox }}, \ldots$, exceeds zero.

c. John is more optimistic than pessimistic: The number of dimensions along which John is optimistic exceeds the number of dimensions along which he is pessimistic.

\footnotetext{
${ }^{1}$ Describing in detail a formal model and the ways it addresses philosophical arguments against dimensions would demand more space than allocated for this paper. See Sassoon (2013a) for extensive discussions.
} 
d. John is more (of) a linguist than a psychologist: The number (or proportion) of dimensions of a linguist whose membership norm John exceeds is higher than the number (or proportion) of dimensions of a psychologist whose norm he exceeds.

These paraphrases suggest that comparison morphemes involve quantification over or counting of dimensions. In other words, it follows from $(6 \mathrm{a}, \mathrm{b})$ that a degree difference in at least SOME dimensions of an adjective should be present for within noun comparisons to hold true. In positive multidimensional adjectives, such as healthy, the requirement might be stronger to the extent that a degree difference should generally be present in ALL or MOST of the dimensions. Furthermore, it follows from $(6 c, d)$ that a larger NUMBER or PERCENTAGE of dimensions of a predicate in comparison to another predicate should be observed in an entity for the comparison to hold true. Without of, the comparison in (6d) appears ambiguous between such an interpretation, which seems especially accessible for American English speakers, and an alternative one, whereby the relative similarity of John to the prototypes of linguist and psychologist compare. Intuitively, John may have neither properties of linguists nor of psychologists, but could still resemble their prototypes to different extents. This would hold true if he is, for instance, a typical philosopher, or maybe a child (Sassoon 2015).

A large body of data suggests that in categorization, the degree functions of the nominal dimensions by default combine to form a single similarity function through averaging operations such as weighted sums or products, as assumed in psychological similarity theories (cf., Sect. 1.2). By contrast, the degree functions of adjectival dimensions appear by default to combine through counting operations, such as those that formal, logical theories assume for quantifying expressions like ALL, MOST or SOME (cf., Sect. 1.3). Thus, the hypothesis presented in (7) emerges:

(7) a. The Quantificational Hypothesis: In within-predicate comparisons (cf., $(6 a, b),(3))$, other degree constructions such as those in (1), and possibly also between-noun comparisons like $(5 \mathrm{a}, \mathrm{b})$, the degree morpheme combines with the dimensions of the predicates via a counting operation (quantifier) in its semantics.

b. The reduced acceptability of nouns: If the dimensions of a predicate are already bound by similarity operations, it is impossible or hard for a quantifier to access and bind them. As a result of this impossibility (or extra processing cost involved in overriding the similarity operations), acceptability reduces.

The following tests suggest that the dimensions of multidimensional adjectives are more accessible for grammatical operations, and in particular for quantifiers, to operate on, than those of nouns (Bartsch 1986; Landman 1989; Sassoon 2013a). Linguistic labels of operations on dimensions include prepositions, as in (8a), quantifiers, as in (8b), exception phrases, as in (8c), and quantifying adverbs, as in (8d), which on the relevant reading convey that their adjectival argument holds in all (or most) respects. The dimensions of nouns, by contrast, are not easily 
accessible in this way, as the reduced acceptability of the nominal examples in (9) illustrates.

(8) a. healthy with respect to blood pressure; good in math.

b. healthy in \{some, most, every\} respect(s); different in three respects.

c. healthy except for high cholesterol; identical except in two respects, size and color.

d. perfectly healthy; $\{$ mostly, completely, totally $\}$ different.

(9) a. \#bird with respect to size; \#dog in movement.

b. \#tiger in \{some, most, every\} respect(s); \#table in three respects

c. \#is a bird except for size; \#is a snake except in two respects, length and color.

d. \#perfectly (a) pine; \#\{mostly, completely, totally $\}$ a duck.

Accordingly, the within-predicate comparison morpheme (-er or more) and similar degree morphemes, may denote operations on dimensions which are incompatible with nouns. This is presumably because their dimensions are already bound by similarity operations and thus inaccessible, as stated in (7b). Moreover, according to the quantificational hypothesis presented in (7), the acceptability of within-predicate comparisons (e.g., $(6 a, b)$ and $(5 c, d)$ ) should correlate with the acceptability of constructions involving quantification over dimensions, such as those in (8)-(9). This is because it is hypothesized that the same problem underlies the reduced acceptability of nouns in all cases. The acceptability of these constructions is assumed to depend on the accessibility of the dimensions, namely, the possibility for a quantifying operation to bind them. These predictions extend to similar degree constructions, such as those in (1), and possibly to between-predicate constructions, if those indeed have interpretations such as those in (6c, d). Finally, presumably, mediation by morphemes such as of raises acceptability, because these morphemes combine with the noun to prepare a set of dimensions for more to operate on. Thus, labor is divided between the two morphemes. However, dimension accessibility may still affect processing and thus acceptability.

Much theoretical work is needed to develop this idea and much experimentation to test it as well. However, this paper focuses on the more basic, general motivation for the quantificational hypothesis. To better understand the determinants of dimension accessibility, the following two sections review studies of the role of dimensions and dimension-binding operations in categorization. We start by discussing the role of similarity operations in categorization under nouns.

\subsection{Psychological Theories of Similarity-Based Categorization}

Consider, for example, ordinary concepts such as games. The intuition that all members of such concept categories have something in common has been prevalent 
since antiquity. It led to the domination of the classical view of categorization and predicate interpretation as based on definitions, namely necessary and sufficient conditions for membership in the extension. Wittgenstein (1953) encouraged his readers to check whether games such as board games, Olympic games, and word games, have anything in common. This move has led many to reject the classical view on the grounds that definitional properties are rarely, if ever, found. For example, one might think of a game as a physical activity, but this is not valid for chess. One might consider competition against opponents, but solitaire does not involve any opponents. Winning and losing characterize solitaire, but when a child throws a ball at the wall they too disappear. Thus, a member of a natural category may share a slightly different set of properties with each other member. Generally, resemblances between members are much like resemblances between family members.

This conception of categorization in terms of family resemblance triggered the development of fruitful experimental paradigms, including extensive work within cognitive psychology (for a review see Murphy 2002) This work has shown that speakers associate concepts with sets of dimensions, and they systematically consider entities that score highly in these dimensions better examples than others of the concepts in question. For example, some of the bird dimensions include having feathers, wings, beak, small size, egg-laying, flying, singing and perching. Thus, a robin is considered more typical or representative of a bird than an ostrich (Rosch 1973). When subjects are asked to rate an item by typicality their ratings are relatively similar, and typicality differences between members can be measured with great reliability if one combines the responses of a group of raters (McCloskey and Glucksberg 1978). Furthermore, typicality is a strong predictor of categorization probability (Hampton 1998). and speed (Rosch 1973); e.g., the verification of sentences like a robin is a bird is faster than of sentences like an ostrich is a bird. But in a context such as the bird walked across the barnyard, for which a chicken is regarded as a typical bird, categorization is faster for chicken than for robin (Roth and Shoben 1983).

These results motivated the prototype theory, which models conceptual structure via a set of weighed dimensions and selected dimensional values that characterize what the best example $\mathrm{p}$ of that concept is like, whether such an object exists or not. Each dimension $\mathrm{F}$ has a weight $\mathrm{W}_{\mathrm{F}}$ (e.g., $\mathrm{W}_{\text {flying }}$ tells us how important flying is in classification) and a selected value, $\mathrm{f}_{\mathrm{F}}(\mathrm{p})\left(\mathrm{e} . \mathrm{g} ., \mathrm{f}_{\text {size }}\left(\mathrm{p}_{\text {bird }}\right)\right.$ represents the ideal size for birds), or range of values (e.g., characteristic colors for apples). The typicality of an item d in a category like bird is modeled by d's similarity to the prototype of bird, $\mathrm{p}_{\text {bird }}$; e.g., the similarity of a robin to a bird is indicated by its averaged degree in the bird dimensions: How well its values match the prototypical values in the dimensions. Since instances of a concept may resemble the prototype in some properties or others, but not necessarily in all its properties, similarity among them is described as family resemblance.

Categorization, following this view, is a process of deciding whether an entity is similar enough to a concept's prototype. Thus, the tight coupling between similarity and membership is captured (Hampton 1998, 2007). Moreover, newly encountered 
entities which average better than known members are correctly predicted to be automatically regarded as category members. Thus, this account captures the fact that we are able to categorize infinitely many new instances under the concepts we are familiar with, based on a finite set of encoded dimensions and members. Classification of atypical instances is slower because they have low degrees in the dimensions. Thus, more dimensions have to be considered to determine membership.

Two main types of similarity functions, additive and multiplicative, are relevant to us, because, as we will shortly explain, nouns associated with them are predicted to exhibit different levels of dimension accessibility. Additive Similarity can be modeled as the weighted sum of x's dimensional degrees, as in (10) (Rosch and Mervis 1975), ${ }^{2}$ while multiplicative similarity can be modeled by the weighted product of x's dimensional degrees, as in (11) (Medin and Schaffer 1978).

(10) Additive similarity: $\mathrm{S}(\mathrm{x}, \mathrm{p})=\mathrm{w}_{\mathrm{F} 1} \mathrm{f}_{\mathrm{F} 1}(\mathrm{x})+\cdots+\mathrm{w}_{\mathrm{Fn}} \mathrm{f}_{\mathrm{Fn}}(\mathrm{x})$

(11) Multiplicative similarity: $S(x, p)=f_{F 1}(x)^{\mathrm{W}_{F 1}} \times \cdots \times f_{F n}(x)^{W_{F n}}$

Multiplication models cases in which the most radical decrease in similarity is between entities which perfectly match the ideal in all the dimensions and entities which mismatch in just one or very few dimensions. For instance, assuming, for simplicity, equal dimensional weights and dimensional degrees between 0 and 1 , then even instances which match in all of the dimensions except for a 0.5 score in one dimension, have a low mean similarity, 0.5 , because multiplication yields 0.5 $\times 1 \times \cdots \times 1=0.5$ (Murphy 2002). Two 0.5 scores yield a mean similarity of 0.25 , and so on. The decrease predicted by additive similarity is by far less drastic.

For example, each bird sub-species is associated with a bundle of dependent or interrelated dimensions, such as shape, color, behavior, genetic layout, inner biological function and offspring characterization. Multiplication models the fact that a shift in one dimension is usually sufficient to justify classification in a different sub-species; e.g., all robins resemble prototypical robins in being small, eating seeds and fruit, and communicating by singing, whereas all eagles resemble prototypical eagles in being big, eating animals, and communicating with calls. An entity which is somewhat a robin and somewhat an eagle would not classify as either and would, instead, classify as a new species. Thus, multiplicative similarity is recognized by a tendency for interrelated dimensions and gaps between categories, whereas additive similarity is recognized by independent dimensions and category overlaps; e.g., a scholar with some properties of a linguist and some properties of a philosopher may well count as both.

To study dimension integration in different noun domains, Hampton, Storms, Simmons and Heussen (2009) invented scenarios with borderline cases. In one scenario, a historical nuclear accident nearby a remote island resulted in the

\footnotetext{
${ }^{2}$ With binary dimensions (dimensions denoting functions from entities to 0 or 1 ), and weights indicated by the number of category members satisfying them $\left(\mathrm{W}_{\mathrm{F}}=\mathrm{I}[[\right.$ bird $\left.]] \cap[[\mathrm{F}]] \mathrm{I}\right)$, similarity reduces to x's family-resemblance score-the number of dimensions all-members share with x (cf., Tversky 1977).
} 
evolution of hybrid creatures, e.g., a sub-kind with some features of lobsters and some features of crabs. In a second scenario, a secluded community in a remote area had the habit of using artifacts in ambiguous ways. For instance, some pieces of clothing had features of both a scarf and a tie. Participants were asked to help scientists classify the entities. In line with multiplicative-similarity, hybrids of two natural kinds were often classified as neither one of the kinds. By contrast, in line with additive similarity, hybrids of social categories were often classified as belonging to both categories.

In an additional study, categorization under labels of artifacts and human traits, unlike animals and plants, appeared often to be based on a simple counting strategy, i.e., on whether entities were within the norm in some (or most) of the concept's dimensions (Wattenmaker 1995). This was modeled with additive similarity, assuming binary dimensions (dimensions which denote functions from entities to 1 or 0 ) of equal weights. This case is unique in that the effect of averaging can be represented via quantifiers. A social noun $\mathrm{N}$ is interpreted as denoting the property that an entity $x$ has if and only if $x$ is within the membership norm $\left(f_{F}(x)=1\right)$ in SOME (or MOST) of N's dimensions. This property discerns social nouns from natural-kind nouns, in which categorization is based on multiplicative similarity (a weighted product, rather than sum, as in (11)), so that even a representation of their dimensions as binary and of equal weights does not yield classification based on dimension counting. Thus, given the quantificational hypothesis in (7), social nouns are predicted to be more compatible than natural-kind nouns, not only with quantificational dimension-binding operations, such as those in (8)-(9), but also with degree morphemes such as those in (1)-(6).

Notice, however, that the adjective-noun distinction confounded the results of Wattenmaker's 1995 study. Most of the social concepts in his experiments were adjectives applicable to humans, and most of the natural kind concepts were nouns. Thus, the reported findings indirectly support the view that adjectives and social nouns, but not natural-kind nouns, may be interpreted by means of quantification (dimension counts). The next section reviews linguistic data suggesting that quantification over dimensions is indeed prevalent in categorization under adjectives. But this methodological issue highlights a broader point. To achieve better understanding of the complexity of language cognition, a need arises for tighter collaboration between linguists and psychologists. This need is precisely what this book is meant to address.

\subsection{Logical Operations of Quantification Over Dimensions in Adjective Categorization}

Consider, for example, the adjective identical. Native speakers intuitively judge entities as identical if and only if they are identical in all (or most) of the respects that count as relevant in the context. By contrast, they intuitively judge entities to be 
different if and only if they are different in some (at least one) respect. Objects are considered clean if and only if dirt of no sort (dust, stains, etc.) is attested on them, while they are considered dirty if and only if dirt of some sort is attested. Individuals with a slight cold are not strictly speaking healthy, since they are not all healthy, while one type of sickness suffices to count as sick.

Considering these, among many other examples, the following hypotheses emerge. First, the dimensions of adjectives seem to be integrated using quantification or counting operations. Second, the dimensions of positive adjectives (like, e.g., identical, healthy and clean) appear, as a default, to be integrated by means of universal quantifiers (ALL, NO). By contrast, those of their negative antonyms appear to be integrated by existential quantifiers (SOME). In other words, intuitively, to count as healthy, one cannot have any serious disease, whereas to count as sick, one must have some disease or other. Hence, healthy seems to mean healthy in ALL respects while sick means sick in SOME respects. We may consider someone to be healthy (or not to be sick) despite, say, high cholesterol only when this dimension is considered irrelevant. When using expressions like all or everybody, the standard practice is to ignore irrelevant entities (von Fintel 1994), but not to allow any other exceptions. Moreover, the discourse in a given context may revolve around cholesterol problems, for example, such that healthy and sick would associate uniquely with this dimension. Thus, positive adjectives also have weak interpretations.

Several corpus and judgment studies (Sassoon 2012, 2013b; Shamir 2013) explored these hypotheses. They suggest that, indeed, universal and existential quantification on dimensions is general among positive and negative adjectives, but rare in concrete nouns. The methodology exploited the fact that exception phrases indicate universal generalizations (generalizations, unlike existence statements, can have exceptions). This fact is illustrated by the higher acceptability of $(12 a, b)$ than of (12c, d) (von Fintel 1994; Hoeksema 1995; Moltmann 1995; Fox and Hackl 2006). Notice that, as logical theories predict, negated existential quantifiers are universal (cf., (12b)), and negated universal quantifiers are existential (cf., (12d)).
a. Everyone is happy except for Dan
b. No one is happy except for Dan
c. \#Someone is happy except for Dan
d. \#Not everyone is happy except for Dan

Accordingly, speakers tend to accept exception phrases with adjectives whose dimensions combine via an implicit universal quantifier ALL, but not with their negative antonyms, whose dimensions combine via an existential quantifier SOME, cf. the acceptability contrast in (13a, c) (Hoeksema 1995). And since negated existential quantifiers are universal and vice versa, the effect is reversed in the presence of negation. Hence, exception phrases tend to be accepted with negated existential adjectives, but not universal ones, as illustrated in (13b, d). 
(13) a. I am healthy except for high blood pressure (bp) $(\forall \mathrm{F} \neq b p$, I'm healthy in F).

b. He is not sick except for the flu $(\neg \exists \mathrm{F} \neq$ flu, He's sick in $\mathrm{F} / \forall \mathrm{F} \neq$ flu, He's healthy in F).

c. \#I am sick except for normative blood pressure (\# $\exists F \neq b p, \neg(I ’ m$ healthy in F)).

d. \#I am not healthy except for (normal) cholesterol (\# $\exists \mathrm{F} \neq \mathrm{ch}, \neg(\mathrm{I}$ 'm healthy in F)).

These judgments are supported by distributional patterns, as revealed in a study of 1300 naturally occurring examples of the form 'Adj. except' with 8 antonym pairs in positive versus negated contexts (Sassoon 2013b). Frequency of co-occurrence of an adjective with dimensional exception phrases depended both on adjective polarity (positive vs. negative) and context polarity (existence or absence of negation), which interacted significantly ( $p<0.001)$. Universality, i.e., frequency of implicit universal quantification on dimensions, as measured by the frequency of exception phrase modification of an adjective in contexts without negation, was higher in positive adjectives (cf., (13a)) than in their negative antonyms (cf., (13c)), whereas existentiality, i.e. frequency of implicit existential quantification on dimensions, as measured by frequency of exception phrase modification of an adjective when negated, was higher in negative adjectives (cf. (13b)) than in positive ones (cf. (13d)). Moreover, in positive adjectives, universality was higher than existentiality, but in negative adjectives, it was lower.

These patterns were also reflected in survey results (Sassoon 2012). They support the view that negative antonymy systematically affects the force of quantifier on dimensions. The dimensions of positive adjectives tend to be bound by a universal quantifier, ALL or NO, while those of negative antonyms tend to be bound by an existential quantifier, SOME. In other words, by default, multidimensional adjectives are used to convey generalizations on dimensions, while multidimensional antonyms relate to counterexamples to such generalizations. Moreover, Shamir (2013) directly compared adjectival antonyms to concrete nouns, showing that these nouns are less acceptable with dimensional exception phrases than either positive or negative adjectives, in both negated and non-negated contexts ( $\mathrm{p}<0.000$; cf. \#bird/not a bird, except for flying/size/wings), in line with dimension binding via similarity operations, instead of quantification.

At the same time, context can override the tendency for similarity-based dimension binding; e.g., in a scientific context in which birdhood is defined by means of $\mathrm{n}$ genes, it is acceptable to state that a certain exemplar is a bird except with respect to 3 genes. Similarly, Sassoon's (2013b) corpus results illustrate that context can override the tendency for universal and existential quantification in positive and negative adjectives, respectively. This is also evident from certain intuitive judgments; e.g., both the combination of smart and of stupid with except in math are natural, and so is The ipad is a bigger iphone except you can't make calls. In addition, the likelihood of multiplicative versus additive dimension-binding in Wattenmaker's (1995) study was affected by the order of presentation (the number 
of preceding additive vs. multiplicative predicates). Other contextual factors await future research (see one pilot in Sassoon 2012).

Returning to default contexts, we have seen that dimension-binding in nouns is mostly based on averaging functions (weighted-sums or -products), rather than quantifiers. This is in accord with the fact that the noun dimensions are normally neither necessary nor sufficient conditions for categorization (Hampton 1995 ). Noun dimensions are often binary (e.g., 'wings' and 'beak' for birds) and many. In contrast to adjectives, conceptual gradability in nouns emerges due to averaging on many of them, not due to counting or to a choice of a single scalar dimension. Adjectives, by contrast, can be represented as having a free dimension argument $\mathrm{F}$. This argument can be saturated as in clever in doing math, which denotes the property of having higher than normal ability to do math, assuming math to be a dimension of clever. Alternatively, the dimension argument can be bound by an explicit or implicit quantifying expression as in vital in every respect or atypical in two respects.

Moreover, the dimension argument can be bound by comparison morphemes; e.g., more in $X$ is more expensive than $Y$ selects the unique member of the dimension-set of expensive (a function from entities to their cost), and returns the relation of being more costly (that relation between $\mathrm{x}$ and $\mathrm{y}$ such that for SOME dimension $\mathrm{F}$ of expensive, $\mathrm{x}$ is F-er than y; cf., (6a)). With the multidimensional adjective healthy, comparison can be along more dimensions; e.g., healthier can denote a relation between entities $\mathrm{x}$ and $\mathrm{y}$ such that for ALL health dimensions $\mathrm{F}, \mathrm{x}$ is F-er than y (cf., (6b); for detailed compositional derivations see Sassoon 2014). The hypothesis in (7) proposes that the acceptability of predicates in such constructions depends on the accessibility of their dimensions, namely the extent to which their interpretation can be modeled by means of a dimension argument bound by a quantifier. Here are a number of its testable predictions.

Most importantly, a continuum of (un)acceptability is predicted. All nouns are predicted to be less acceptable than adjectives in within-predicate comparisons, because, by default, their dimensions are bound by averaged similarity operations and thus are not accessible for quantifiers to bind. However, additive nouns are expected to be more acceptable than multiplicative nouns, because under certain assumptions their interpretation can turn to one based on dimension counting. Thus, nouns denoting social categories are expected to be more acceptable than nouns denoting animals and plants (cf., (14c-d) vs. (14a-b), respectively). In addition, if between-noun comparisons exhibit the same continuum (cf., (15c) vs. (15a)), this will support the availability of a reading involving comparison of the number of dimensions of each compared predicate, whose norm an entity exceeds (cf., (6c, d)). But if their only reading directly exploits degrees of similarity of entities to nominal prototypes, no acceptability difference between social and natural-kind nouns is expected.

Similar contrasts are expected to occur also with quantifiers on dimensions and exception phrases that weaken generalizations on dimensions, as in (16) and (8)(9). Moreover, if comparisons indeed involve quantification on dimensions, then the acceptability of a predicate in comparison constructions and in quantificational constructions, as in (16), is expected to correlate. 
(14) Within-noun comparisons: "X is more NP than that Y"
a. \#This piece of fruit is more an orange than that piece of fruit.
b. \#This farm animal is more a cow than that farm animal.
c. ?This booklet is more a diary than that booklet.
d. ?This artist is more a composer than that artist.

(15) Between-noun comparisons: " $\mathrm{X}$ is more $\mathrm{NP}_{1}$ than $\left(\mathrm{Y}\right.$ is) $\mathrm{NP}_{2}$ "
a. ?This piece of fruit is more an orange than an apple
b. ?This farm animal is more a cow than that farm animal is a horse
c. This booklet is more a diary than a sketchbook
d. This artist is more a composer than that artist is a poet

(16) Dimensional exception phrases: " $\mathrm{X}$ is (not) NP, except for/with respect to DIM"
a. \#This vegetable is (not) a potato except for color.
b. \#This predator is (not) a tiger except for its teeth number.
c. ?This place is (not) a church except in appearance.
d. ?This girl is (not) a genius except with respect to literature.

Finally, within-noun comparisons (cf., (14)) are expected to be less acceptable than single-subject between-noun comparisons (cf., (15a, c)). The latter seem to have a reading that directly exploits the similarity functions underlying categorization in nouns, while the former do not, presumably because they only select for dimensions compatible with difference modifiers (interval-scale dimensions), as in two inches longer and slightly shorter (Sassoon 2013a). Even relatively abstract adjectives seem to allow for an interval-scale construal (e.g., slightly happier, a lot more beautiful), whereas nouns appear to refuse it and are mostly based on nominal dimensions (e.g., wings: yes/no) or ordinal dimensions (movement type: flying $>$ swimming $>$ running; Gardenfors 2004). Two-subject between-predicate comparisons (cf., (15b, d)) are also expected to dislike nouns as they seem to license difference modifiers (e.g., The sofa is 2 inches longer than the table is wide), as opposed to single-subject comparisons (e.g.,, $(15 \mathrm{a}, \mathrm{c}))$ which seem to be incompatible with difference modifiers (cf., \#slightly/\#a lot more a car than a truck; Morzycki 2011). The judgment study we now turn to aims to test some of these predictions.

\section{A Pilot Study of Acceptability Judgments}

\subsection{Method}

The participants were recruited using Amazon mechanical Turk (AMT), an online labor market place where workers are paid small amounts of money to complete small tasks named HITs (Human Intelligence Tasks). It has been shown that AMT provides a quick and relatively cheap method to acquire high-quality experimental 
results that do not differ significantly in performance from standard experimental settings (Buhrmester et al. 2011). The hits were only visible to American workers with approval rates exceeding 95\%. They were awarded 2 cents per hit consisting of a single item rating, with an average hourly rate of $6.5 \$$. A group of 25 different participants completed each hit. Once 25 participants filled out a hit, it was no longer visible. Moreover, each participant chose how many hits to fill out. In total, 140 participants answered an average of 44.5 different questions each $(\mathrm{SD}=58)$. All hits were completed on 18/07/2013.

The stimuli were sentences formed of 24 definite noun phrases that served as subjects and 24 indefinite noun phrases that served as predicates, such as, for example, This farm animal and a cow, respectively, in This farm animal is more a cow than that farm animal. The factors manipulated were entity type-half of the subjects (and their predicates) denoted natural entity types (plants and animals) and half denoted social entity type (human traits and artifacts), and structure-each subject-predicate combination occurred in 7 different constructions. These constructions were: (i) two baseline conditions (Pos, Not) including basic and negated categorization forms (' $\mathrm{x}$ is $\mathrm{P}$ ' and ' $\mathrm{x}$ is not $\mathrm{P}$ '); (ii) three comparison conditions (Within, Be1s, Be2s) including within-noun comparisons (' $\mathrm{x}$ is more $\mathrm{P}$ than $\mathrm{y}$ '; cf., (14)), single-subject between-noun comparisons (' $\mathrm{x}$ is more $\mathrm{P}$ than $\mathrm{Q}$ ', as in (15a, c)), and two-subject between noun comparisons (' $\mathrm{x}$ is more $\mathrm{P}$ than $\mathrm{y}$ is $\mathrm{Q}$ ', as in $(15 \mathrm{~b}, \mathrm{~d})$ ); and (iii) two modified forms (Ex, ExNot) including basic and negated forms with dimensional exception phrases (' $\mathrm{x}$ is $\mathrm{P}$ except for Dim' and ' $\mathrm{x}$ is not $\mathrm{P}$ except for Dim', as in (16)).

An eighth condition consisted of within-adjective comparisons, constructed by applying each one of 6 positive one-dimensional adjectival predicates (tall, heavy, big, old, expensive and colorful) to 4 of the 24 subjects, an animal, plant, artifact and human trait. Thus, focusing on the within-predicate comparisons, the factors manipulated were Predicate type (adjective vs. noun) and Entity type (social vs. natural). ${ }^{3,4}$

In comparisons with two entities, the two were always described as This $N P$ and That NP (as in This artist is more a composer than that artist.) In comparisons with two predicates, each nominal predicate was matched with a contrasting predicate (e.g., duck and goose; dress and night shirt; see Table 1 for the full set of subjects and contrasting predicate pairs). The matched pairs were mostly withdrawn from the stimuli reported in Hampton, Storms, Simmons and Heussen (2009). The pairs of human traits and professions were chosen from a list created by searching the

\footnotetext{
${ }^{3}$ An additional factor was Than-phrase type - half of the sentences with each entity and predicate type included a clausal than-phrase and half included a phrasal one, as in This animal is taller than that animal is versus This person is taller than that person, respectively.

${ }^{4}$ Here is a set of examples for each of the 8 conditions: (1) This place is a church; (2) This place is not a church; (3) This place is more a church than that place is; (4) This place is more a church than an art gallery; (5) This place is more a church than that place is an art gallery; (6) This place is a church except in appearance; (7) This place is not a church except in appearance; (8) This place is older than that place is.
} 
Table 1 The 24 between noun comparisons with a single subject

\begin{tabular}{|c|c|c|c|}
\hline \multicolumn{4}{|c|}{ Natural entity types } \\
\hline \multicolumn{2}{|c|}{ Animals } & \multicolumn{2}{|c|}{ Plants } \\
\hline 1 & $\begin{array}{l}\text { This farm animal is more a cow than a } \\
\text { horse }\end{array}$ & 1 & This tree is more a pine than an oak \\
\hline 2 & $\begin{array}{l}\text { This insect is more a mosquito than a } \\
\text { wasp }\end{array}$ & 2 & $\begin{array}{l}\text { This vegetable is more a potato than a } \\
\text { carrot }\end{array}$ \\
\hline 3 & This bird is more a crow than a pigeon & 3 & $\begin{array}{l}\text { This flower is more a dandelion than a } \\
\text { rose }\end{array}$ \\
\hline 4 & This reptile is more a snake than a lizard & 4 & This spice is more onion than mint \\
\hline 5 & This predator is more a wolf than a tiger & 5 & This plant is more moss than grass \\
\hline 6 & $\begin{array}{l}\text { This aquatic mammal is more a dolphin } \\
\text { than a shark }\end{array}$ & 6 & $\begin{array}{l}\text { This piece of fruit is more an orange } \\
\text { than an apple }\end{array}$ \\
\hline \multicolumn{4}{|c|}{ Social entity types } \\
\hline \multicolumn{2}{|c|}{ Human concepts } & \multicolumn{2}{|c|}{ Artifacts } \\
\hline 1 & $\begin{array}{l}\text { This journalist is more a consultant than } \\
\text { a reporter }\end{array}$ & 1 & $\begin{array}{l}\text { This place is more a church than an art } \\
\text { gallery }\end{array}$ \\
\hline 2 & $\begin{array}{l}\text { This artist is more a composer than a } \\
\text { poet }\end{array}$ & 2 & $\begin{array}{l}\text { This piece of clothing is more a dress } \\
\text { than a nightshirt }\end{array}$ \\
\hline 3 & $\begin{array}{l}\text { This football player is more a champion } \\
\text { than a celebrity }\end{array}$ & 3 & $\begin{array}{l}\text { This car is more a taxi than an } \\
\text { ambulance }\end{array}$ \\
\hline 4 & This girl is more a genius than a child & 4 & $\begin{array}{l}\text { This hall is more a theatre than a } \\
\text { cinema }\end{array}$ \\
\hline 5 & $\begin{array}{l}\text { This colleague is more a businesswoman } \\
\text { than a friend }\end{array}$ & 5 & $\begin{array}{l}\text { This container is more a carafe than a } \\
\text { vase }\end{array}$ \\
\hline 6 & $\begin{array}{l}\text { This person is more a victim than a } \\
\text { witness }\end{array}$ & 6 & $\begin{array}{l}\text { This booklet is more a diary than a } \\
\text { sketchbook }\end{array}$ \\
\hline
\end{tabular}

corpus of contemporary American English (Coca, Davies 2010) for the string "(s)he is a" followed by a noun. Unfortunately, two errors occurred in the survey: 'crew' and 'fly' were used instead of 'crow' and 'insect', respectively. Thus, the results are reported with these two items removed.

The 192 target sentences $(24 \times 8$ conditions $)$ with 57 additional good and bad fillers of various forms can be found in Appendix 1. The 249 sentences (hits) were presented as a single randomly ordered list, out of which different participants filled out different subsets. The variables are therefore within-subject, but with many missing observations.

The following instructions occurred in every hit: "[This hit is for English Native Speakers Only] RATE THE FOLLOWING SENTENCES BY HOW NATURAL THEY SOUND TO YOU AS AN ENGLISH NATIVE SPEAKER. FOR EXAMPLE: (i) To me, the sentence "This child is rarely sick" is a perfectly natural sentence, so I give it '7'; (ii) However, the sentence "This child is rarely tall" is perfectly unnatural and makes no sense (me or my friends would never use such a combination of words), so I give it ' 1 '". Following the instructions the participants saw a sentence and a 7-point scale with the labels PERFECTLY NATURAL and 
PERFECTLY UNNATURAL adjacent to 7 and 1, respectively. They selected an answer by clicking on the radio button adjacent to the relevant number.

\subsection{Results}

The mean naturalness and standard deviation for each condition are presented in Table 2 (for more detailed tables by items see Appendices A-B). The two left columns of Table 2 reveal a potential interaction between structure and entity type. As predicted, nominal structures involving comparison (conditions 1-3) and exception-phrases (conditions 4-5) were rated as more natural with social items (subjects and predicates) than with natural items (e.g., more a composer was rated higher than more a pine, and a diary except for the sketches was rated higher than $a$ potato except for color). However, no such differences were found in adjectival comparisons (condition 6) (e.g., taller) and basic categorization structures (7-8) (e.g., is a pine/composer).

The right column further suggests that within-adjective comparisons (condition 6), are more natural than single-subject between-noun comparisons (condition 1), which in turn are more natural than within-noun comparisons (condition 2). The least natural seem to be the two-subject between noun comparisons (condition 3).

To test whether these potential effects and interactions are significant, the results of the 7 nominal conditions were analyzed using a variety of mixed models with naturalness as the dependent variable and participant and item (22 subject + predicate combinations) as random effects. This type of analysis tests whether the

Table 2 Averages and standard deviations by condition for 10 natural items (subjects + predicates), 12 social items, and all 22 items

\begin{tabular}{l|l|l|l}
\hline Conditions & $\begin{array}{l}\mathrm{M}_{\text {natural }} \\
(\mathrm{SD})\end{array}$ & $\begin{array}{l}\mathrm{M}_{\text {social }} \\
(\mathrm{SD})\end{array}$ & $\begin{array}{l}\mathrm{M}_{\text {total }} \\
(\mathrm{SD})\end{array}$ \\
\hline $\begin{array}{l}\text { 1. Single subject between-noun comparisons (Be1s): } \\
\text { More NP1 than NP2 }\end{array}$ & $\begin{array}{l}3.94 \\
(2.10)\end{array}$ & $\begin{array}{l}5.23 \\
(1.90)\end{array}$ & $\begin{array}{l}4.64 \\
(2.09)\end{array}$ \\
\hline 2. Within-noun comparisons (Within): & 3.38 & 4.46 & 3.97 \\
More NP than Y (is) & $(1.98)$ & $(2.00)$ & $(2.06)$ \\
\hline 3. Two-subject between-noun comparisons (Be2s): More NP & 2.76 & 3.15 & 2.97 \\
than y is NP & $(1.74)$ & $(1.90)$ & $(1.84)$ \\
\hline 4. Exception phrases (Ex): & 2.86 & 3.51 & 3.21 \\
X is NP except & $(1.92)$ & $(2.09)$ & $(2.04)$ \\
\hline 5. Negated exception phrases (ExNot): & 2.66 & 3.54 & 3.14 \\
X is not NP except & $(1.80)$ & $(2.12)$ & $(2.03)$ \\
\hline 6. Within-adjective comparisons (Adj): & 6.08 & 6.02 & 6.05 \\
More AP than Y (is) & $(1.58)$ & $(1.58)$ & $(1.58)$ \\
\hline 7. Basic categorization (Pos): & 6.44 & 6.58 & 6.52 \\
X is NP & $(1.28)$ & $(1.00)$ & $(1.14)$ \\
\hline 8. Negated categorization (Not): & 6.49 & 6.54 & 6.52 \\
X is not NP & $(1.24)$ & $(1.15)$ & $(1.19)$ \\
\hline
\end{tabular}


manipulated factors explain anything more than what could be predicted on the basis of the participants and the stimuli. It is reasonably robust against influence of a single outlier item or participant, and against missing observations (Baayen et al. 2006).

The baseline and comparison conditions were compared using a mixed model with Entity type (natural vs. social) and Structure (Basic vs. Comparison) as fixed effects. A structure effect and an interaction were predicted, and indeed a significant main effect was found for both Entity type $(\mathrm{F}(1,20)=12.2, \mathrm{p}=0.002)$ with higher ratings for social $(\mathrm{M}=5.2, \mathrm{SD}=2.1)$ than natural items $(\mathrm{M}=4.6, \mathrm{SD}=2.3)$, and Structure $(\mathrm{F}(1,2660)=1979.9, \mathrm{p}<0.001)$, with higher ratings for basic $(\mathrm{M}=6.5$, $\mathrm{SD}=1.2)$ than comparative structures $(\mathrm{M}=3.9, \mathrm{SD}=2.1)$. Further, the two factors significantly interact $(\mathrm{F}(1,2652)=45.7, \mathrm{p}<0.001)$. Comparative structures were rated higher with social $(\mathrm{M}=4.3, \mathrm{SD}=2.1)$ than natural items $(\mathrm{M}=3.4, \mathrm{SD}=2.0)$, while basic structures with social $(\mathrm{M}=6.6, \mathrm{SD}=1.1)$ and natural items $(\mathrm{M}=6.5, \mathrm{SD}=1.3)$ were rated similarly.

Considering the three comparison conditions more specifically, a mixed model analysis with structure (Within, Be1s, Be2s) and entity type (social vs. natural) as fixed effects confirmed the predicted entity type effect $(\mathrm{F}(1,20)=29.3$, p < 0.001), with higher ratings for social $(\mathrm{M}=4.3, \mathrm{SD}=2.1)$ than natural items $(\mathrm{M}=3.4$, $\mathrm{SD}=2.0)$, and revealed an additional structure effect $(\mathrm{F}(2,1544)=140.7$, $\mathrm{p}<0.001)$. Pairwise comparisons confirmed that, as expected, the naturalness of the single-subject between-noun comparisons $(\mathrm{M}=4.6, \mathrm{SD}=2.1)$ was significantly higher than the naturalness of the within-noun comparisons $(\mathrm{M}=4, \mathrm{SD}=$ 2.1; Mean difference 0.65, $\mathrm{SE}=0.096, \mathrm{df}=1544, \mathrm{p}<0.001$ ), which was significantly higher than the naturalness of the two-subject between-noun comparisons $(\mathrm{M}=3, \mathrm{SD}=1.8$; Mean difference 0.99, $\mathrm{SE}=0.096, \mathrm{df}=1553, \mathrm{p}<0.001)$. Univariate tests based on the pairwise comparisons of marginal means yielded $\mathrm{F}(2$, $1548)=146.9(\mathrm{p}<0.001)$.

The analysis further revealed a significant entity by structure interaction $(\mathrm{F}(2,1548)=13.2, \mathrm{p}<0.001)$, with bigger differences between natural and social items in single-subject between-noun comparisons $\left(\mathrm{M}_{\text {social }}=5.2, \quad \mathrm{SD}=1.9\right.$; $\left.\mathrm{M}_{\text {natural }}=3.9, \mathrm{SD}=2.1\right)$ and within-noun comparisons $\left(\mathrm{M}_{\text {social }}=4.5, \mathrm{SD}=2\right.$; $\mathrm{M}_{\text {natural }}=3.4, \quad \mathrm{SD}=2$ ) than in two-subjects between-noun comparisons $\left(\mathrm{M}_{\text {social }}=3.2, \mathrm{SD}=1.9 ; \mathrm{M}_{\text {natural }}=2.8, \mathrm{SD}=1.7\right)$. To test these simple entity type effects (illustrated in Fig. 1), separate mixed models were conducted for each structure, with entity type as the fixed effect. The significantly higher naturalness predicted for social versus natural entity types was confirmed in within noun comparisons ('more $\mathrm{N}$ than $\mathrm{y}$ '; $\mathrm{F}(1,24)=13.4, \mathrm{p}=0.001$ ) and single-subject between-noun comparisons ('more $\mathrm{N} 1$ than N2'; $\mathrm{F}(1,28)=15.4, \mathrm{p}<0.001$ ), and it approximated significance in two-subject between-noun comparisons ('more N1 than $y$ is $\mathrm{N} 2$ '; $\mathrm{F}(1,19)=4.3, \mathrm{p}=0.051)$. Importantly, there were no entity type effects in the baselines (for Pos-' $x$ is $P$ ': $F(1,19)=0.377, p=0.546$; for Not- ' $\mathrm{x}$ is not $\mathrm{P}$ ': $\mathrm{F}(1,19)=0.046, \mathrm{p}=0.83$ ) and adjectival condition ('more Adj than $\mathrm{y}$ '; $\mathrm{F}(1,20)=0.122, \mathrm{p}=0.73$ ). Thus, entity type only affected naturalness of nominal comparisons, as predicted. 
Fig. 1 Entity $\times$ Structure interactions: entity type effects (social > natural) occurred in the structures involving nominal comparisons and exception-phrases, while they occurred neither in the basic categorization structures, nor in the adjectival comparison structures

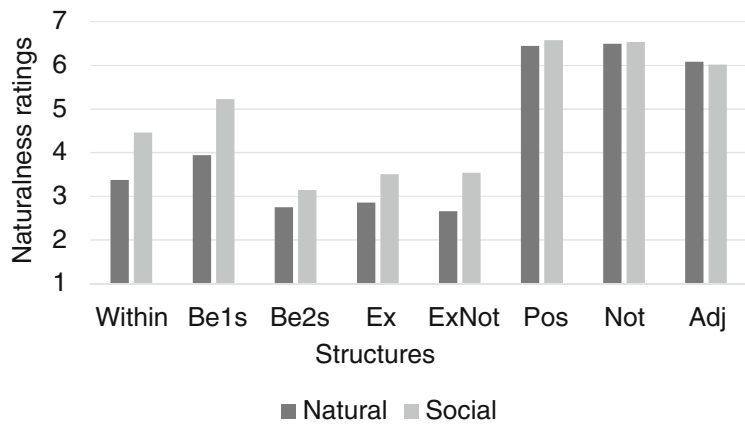

Turning to exception phrases, the baselines (Pos, Not) and modified conditions (Ex: ' $\mathrm{x}$ is $\mathrm{N}$ except in dim', ExNot: ' $\mathrm{x}$ is not $\mathrm{N}$ except in dim') were also compared using a mixed model with Entity type (natural vs. social) and Structure (Basic vs. modified) as fixed effects. Again, a structure effect and an interaction were predicted. While the Entity type effect was only approximating significance $(\mathrm{F}(1,19)=4.3, \mathrm{p}=0.051)$, with higher ratings for social items $(\mathrm{M}=5, \mathrm{SD}=2.3)$ than for natural items $(\mathrm{M}=4.6, \mathrm{SD}=2.4)$, the analysis revealed as predicted a significant Structure effect $(\mathrm{F}(1,2109)=3009.4, \mathrm{p}<0.001)$, with higher ratings for basic structures $(\mathrm{M}=6.5, \mathrm{SD}=1.2)$ than for exceptive structures $(\mathrm{M}=3.2$, $\mathrm{SD}=2)$, and a significant interaction $(\mathrm{F}(1,2106)=27.1, \mathrm{p}<0.001)$. Exceptive structures were rated higher with social items $(\mathrm{M}=3.5, \mathrm{SD}=2.1)$ than with natural items $(\mathrm{M}=2.8, \mathrm{SD}=1.9)$, while basic structures with social items $(\mathrm{M}=6.6, \mathrm{SD}=1.1)$ and natural items $(\mathrm{M}=6.5, \mathrm{SD}=1.3)$ were rated similarly. $^{5}$

Considering the two exceptive structures more specifically, a mixed model analysis with structure (Ex, ExNot) and entity type (social vs. natural) as fixed effects confirmed the predicted entity type effect $(F(1,20)=5.2, p=0.033)$, with higher ratings for social items $(\mathrm{M}=3.5, \mathrm{SD}=2.1)$ than for natural items $(\mathrm{M}=2.8, \mathrm{SD}=1.9)$, and with neither a significant structure effect $\left(\mathrm{M}_{\mathrm{Ex}}=3.21\right.$, $\left.\mathrm{SD}=2 ; \mathrm{M}_{\mathrm{ExNot}}=3.14, \mathrm{SD}=2 ; \mathrm{F}(1,1008)=0.818, \mathrm{p}=0.366\right)$ nor an interaction $(\mathrm{F}(1,999)=2.3, \mathrm{p}=0.131)$. Separate mixed models for each condition revealed that, as Fig. 1 illustrates, the structures with exception-phrases exhibited the entity type effect both with negation $\left(\mathrm{M}_{\text {social }}=3.5, \mathrm{SD}=2.1 ; \mathrm{M}_{\text {natural }}=2.7\right.$,

\footnotetext{
${ }^{5}$ These conditions were also analyzed using Structure (Basic vs. modified) and Negation (yes/no) as fixed effects. Beside the structure effect $(\mathrm{F}(1,2109)=2945.7, \mathrm{p}<0.001)$, there was neither a significant negation effect $(\mathrm{F}(1,2114)=0.585, \mathrm{p}=0.444)$, nor an interaction $(\mathrm{F}(1$, 2102) $=0.324, \mathrm{p}=0.569$ ).
} 
$\mathrm{SD}=1.8 ; \mathrm{F}(1,22)=5.4, \mathrm{p}=0.029)$ and without negation $\left(\mathrm{M}_{\text {social }}=3.5, \mathrm{SD}=\right.$ $\left.2.1 ; \mathrm{M}_{\text {natural }}=2.9, \mathrm{SD}=1.9 ; \mathrm{F}(1,20)=4.49, \mathrm{p}=0.047\right)$. $^{6,7}$

Focusing on within-predicate comparisons with adjectives versus nouns, a mixed model with Entity type (Social vs. Natural) and Predicate type (Adjective vs. Noun) as fixed effects, and participant and item (44 subject + predicate combinations) as random effects, was carried out to test a predicted predicate-type effect and interaction. The test yielded significance for both Predicate type $(F(1,39)=164.2$, $\mathrm{p}<0.001)$, with higher ratings for comparisons within adjectives $(\mathrm{M}=6.1$, $\mathrm{SD}=1.6)$ than nouns $(\mathrm{M}=4, \mathrm{SD}=2.1)$, and Entity type $(\mathrm{F}(1,40)=8.8$, $\mathrm{p}=0.005)$, with higher ratings for comparisons within social items $(\mathrm{M}=5.2$, $\mathrm{SD}=2)$ than within natural items $(\mathrm{M}=4.7, \mathrm{SD}=2.2)$. Further, a significant interaction was manifested as predicted $(\mathrm{F}(1,40)=12.8, \mathrm{p}=0.001)$. While comparisons with social nouns $(\mathrm{M}=4.5, \mathrm{SD}=2)$ were rated higher than with natural nouns $(M=3.4, S D=2)$, comparisons with social adjectives $(M=6$, $\mathrm{SD}=1.6)$ and natural adjectives $(\mathrm{M}=6.1, \mathrm{SD}=1.6)$ were rated similarly. ${ }^{8}$

Finally, recall that comparative structures were hypothesized to resemble structures with dimensional exception-phrases in involving quantification over dimensions. Thus, the naturalness of a predicate in both types of structure was expected to correlate, as its naturalness in both structures was expected to be affected by the accessibility of its dimensions to binding by quantifiers. Thus, analyses by item were conducted to test correlations. Table 3 presents the correlation coefficients and $\mathrm{p}$ values for the comparison by exception-phrase conditions $(\mathrm{n}=22)$. Notice the moderate correlation between the dimensional exception

\footnotetext{
${ }^{6}$ All simple structure effects in comparison constructions were also significant when mixed models were conducted separately for the dataset of natural entity types and for the dataset of social entity types, with structure as the fixed effect.

First, within the natural dataset, structure was significant $(F(2,775)=38.5, p<0.001)$. The naturalness of the single-subject between-noun comparisons was significantly higher than the naturalness of the within-noun comparisons (Mean difference $0.681, \mathrm{SE}=0.134$, $\mathrm{df}=773$, $\mathrm{p}<0.001$ ), which was significantly higher than the naturalness of the two-subject between-noun comparisons (Mean difference $0.499, \mathrm{SE}=0.127$, $\mathrm{df}=776, \mathrm{p}<0.001$ ). Univariate tests based on the pairwise comparisons of marginal means yielded $\mathrm{F}(2,773)=38.5, \mathrm{p}<0.001$.

Second, within the social dataset, structure was significant $(F(2,826)=132.9, p<0.001)$. The naturalness of the single-subject between-noun comparisons was significantly higher than of the within-noun comparisons (Mean difference 0.665, $\mathrm{SE}=0.130$, $\mathrm{df}=826, \mathrm{p}<0.001$ ), which was significantly higher than the naturalness of the two-subject between-noun comparisons (Mean difference $1.403, \mathrm{SE}=0.129$, df $=826, \mathrm{p}<0.001$ ). Univariate tests based on the pairwise comparisons of marginal means yielded $\mathrm{F}(2,826)=132.9, \mathrm{p}<0.001$.

By contrast, in the exception phrase modified constructions, structure was significant neither in the natural dataset $(\mathrm{F}(1,434)=3.28, \mathrm{p}=0.071)$, nor in the social dataset $(\mathrm{F}(1,528)=0.22$, $\mathrm{p}=0.64)$.

${ }^{7}$ With structure as the fixed effect, the exception phrases (Ex, ExNot) didn't differ from the worst comparison, $\mathrm{Be} 2 \mathrm{~s}(\mathrm{~F}(2,1554)=3.4, \mathrm{p}=0.034)$, but scored lower than the within-noun comparison $(\mathrm{F}(2,1551)=44.8, \mathrm{p}<0.001)$.

${ }^{8} \mathrm{~A}$ mixed model with Than-clause type (phrasal vs. clausal) and predicate type (adjective vs. noun) as fixed effects yielded neither a significant Than-clause type effect $(F(1,39)=2.2, p=0.149)$, nor an interaction $(\mathrm{F}(1,39)=3.3, \mathrm{p}=0.076)$.
} 
Table 3 Correlation coefficients for exception phrase by comparison conditions

\begin{tabular}{l|l|l|l|l|l}
\hline \multicolumn{2}{l|}{$\begin{array}{l}\text { Spearman's } \\
\text { rho }\end{array}$} & Be1s & ExNot & Within & Be2s \\
\hline \multirow{2}{*}{ Ex } & $\mathrm{r}^{\mathrm{s}}$ & 0.116 & $0.701^{* *}$ & 0.376 & 0.241 \\
\cline { 2 - 6 } & $\mathrm{p}^{2}$ & 0.6 & $<0.001$ & 0.084 & 0.280 \\
\hline \multirow{2}{*}{ Be1s } & $\mathrm{r}^{\mathrm{s}}$ & 1 & 0.413 & $0.694^{* *}$ & $0.693^{* *}$ \\
\cline { 2 - 6 } & $\mathrm{p}^{2}$ &. & 0.056 & $<0.001$ & $<0.001$ \\
\hline \multirow{2}{*}{ ExNot } & $\mathrm{r}^{\mathrm{s}}$ & & 1 & $0.578^{* *}$ & $0.447^{*}$ \\
\cline { 2 - 6 } & $\mathrm{p}^{2}$ & &. & 0.005 & 0.037 \\
\hline \multirow{2}{*}{ Within } & $\mathrm{r}^{\mathrm{s}}$ & & & 1 & $0.452^{*}$ \\
\cline { 2 - 6 } & $\mathrm{p}^{2}$ & & &. & 0.035 \\
\hline
\end{tabular}

phrases with negation and both the within-noun comparisons (ExNot $\times$ Within: $\left.\mathrm{r}^{\mathrm{s}}=0.58, \mathrm{p}=0.005\right)$ and single-subject between-noun comparison (ExNot $\times$ Be1s: $\left.r^{\mathrm{s}}=0.45, \mathrm{p}=0.037\right)$.

\section{Discussion}

By the quantificational hypothesis presented in (7), the acceptability of predicates in comparative and exceptive constructions depends on the accessibility of their dimensions. In other words, it depends on the extent to which categorization under the concepts they label can be modeled by means of quantification over their dimensions. Given this hypothesis, a continuum of (un)acceptability was predicted. All nouns were predicted to be less natural than adjectives in within-predicate comparisons, because, by default, their dimensions are bound by averaged similarity operations and thus are not accessible for quantifiers to bind. However, additive nouns were expected to be more acceptable than multiplicative nouns, because under certain circumstances their interpretation turns to one based on dimension counting and quantification. Thus, in particular, additive nouns denoting social categories were expected to be more acceptable than multiplicative nouns denoting animals and plants (Hampton et al. 2009).

The results of this study confirmed the predicted continuum. First, within-predicate comparisons (' $\{\mathrm{P}$-er, more $\mathrm{P}\}$ than $\mathrm{y}$ ') were rated as more natural with adjectives like tall or big than with nouns like a composer or pine.

Second, as Fig. 1 illustrates, additive social nouns were rated as more natural than non-additive natural kind nouns in all the comparison constructions tested. The acceptability of nominal comparisons appears to match the degree to which the noun's default interpretation can be approximated by one based on dimensional quantifiers, as hypothesized. This suggests that these constructions involve operations on accessible dimensions. An accommodation of binary dimensions with equal weights renders the interpretation of additive, but not multiplicative nouns, equivalent to one based on quantification. Thus, the former were predicted to be more acceptable in degree constructions. These predictions were borne out. 
Third, similarly, social additive nouns were better than natural-kind multiplicative ones with dimensional exception phrases. The negated condition (as in "not an $\mathrm{N}$ except for dim") indicates the acceptability of dimension binding by an existential quantifier (SOME). By contrast, the non-negated condition ("N except for dim") indicates the acceptability of dimension binding by a universal quantifier (ALL). The two conditions did not differ significantly, suggesting that neither existential nor universal quantification dominates classification in nouns (as in Shamir 2013). But the more a noun resembles an adjective in its default dimension-binding, the more acceptable it seems to be in either exception phrase construction.

Finally, the correlation matrix in Table 3 suggests that a correlation exists between the naturalness of exception phrase modification and comparison, at least in negated nouns. Comparative structures were hypothesized to resemble structures with dimensional exception-phrases in involving quantification over dimensions. Thus, the naturalness of a predicate in both types of structure was expected to correlate, as its naturalness in both structures was expected to be affected by the accessibility of its dimensions to binding by quantifiers.

The fact that this prediction was only confirmed by the negated condition suggests that compatibility with existential quantification is more important in predicting acceptability of nouns in comparisons. Possibly, comparisons are interpreted by existentially binding the dimensions of their predicative argument. Thus, their naturalness correlates with that of a construction that forces a noun to be interpreted as existential on its dimensions. To assess the validity of this interpretation, future research should assess the naturalness of comparative predicates with dimensional exception phrases ("x is (not) more $\mathbf{P}$ than $\mathbf{y}$ except in dim"). If comparative predicates are predominantly existential, higher acceptability is expected in the negated case.

All in all, the results seem to support the quantifying hypothesis. The study has shown that higher likelihood of categorization based on counting and quantification corresponds with higher naturalness in grammatical constructions involving implicit counting or quantification, and those include not only dimensional exception phrases (e.g., tiger (in every respect) except for its teeth number), but also comparisons (e.g., more a pine than $\{$ an oak, that tree, that tree is an oak\}).

However, this study included only positive, one-dimensional, context relative adjectives (e.g., big). Future studies should also consider negative (e.g., small), absolute (e.g., empty, and closed), and multidimensional adjectives. The latter are particularly interesting, because they resemble nouns in having multiple dimensions. As such they form a stricter test for the presented theory. They too are expected to be better than nouns in comparative and exceptive structures, since they are expected to have a higher tendency than nouns toward quantificational binding of their dimensions. One multidimensional adjective (Italian) appeared in the three comparison types, as part of the 57 fillers. Its averaged scores in the within-predicate comparison This film is more Italian than that film, 6.12 (1.21), and two-subject between-predicate comparison This film is more Italian than that film is American, 3.92 (1.79), were by far higher than the average scores of the 
nouns in these comparisons (4.70 and 2.97), as expected. But its score in the single-subject between-predicate comparison This film is more Italian than American, 5.24 (1.68), was similar to the noun scores (4.00). These comparisons appear, indeed, to be especially suited to nouns.

Moreover, this comparison type manifested the least significant correlation. This may stem from the existence of a second reading, as suggested in the discussion of (6d), whereby similarity of an entity to two nominal prototypes is directly compared. This reading does not involve dimension counting, and thus, its contribution to the naturalness judgments is expected to be independent of the naturalness of exception phrases. Its existence is compatible also with the relatively high naturalness of nouns in this construction. At any rate, the clear preference of additive nouns over multiplicative nouns in this comparison does support the existence of a reading based on counting of accessible dimensions, as the paraphrases in (6c-d) suggest.

An anonymous reviewer observed that the between-natural-noun comparisons involved taxonomical hierarchies, e.g., snake and lizard were predicated over reptile and wolf and tiger over predator, whereas some between-social-noun comparisons didn't, e.g., champion and celebrity were predicated over football player. A second reviewer suggested that failure of an implicature may have confounded the results. The suggested implicature is that one of the two compared predicates (e.g., rose and dandelion) applies to the entity in question, but the speaker does not know which. Naturalness may have been reduced by the difficulty of imagining a speaker being unsure of whether a flower is a rose or a dandelion. These potential confounds deserve investigation (e.g., by presenting sentences in contexts where the implicature is either satisfied or not), but they cannot explain why differences between natural and social nouns occurred also in several other constructions, specifically within-noun comparisons and exception phrases, of which the between-noun comparisons were actually more acceptable.

A number of additional issues merit attention. Recall that the embedded clause in the within-predicate comparisons was as in This football player is more a champion than that football player (is), rather than than that one (is). The idea was to block interpretations of that one as relating to a property, which would turn the comparison into a between-noun one, but this feature may have reduced the naturalness of these comparisons, and thus should be eliminated in future studies. Moreover, in the exception phrase conditions, each noun was matched with but one dimension. This fact may have added noise that reduced the significance of the results. Future research should assess judgments for exception phrases with at least 3-4 dimensions per noun or adjective (cf., Sassoon 2012. and Shamir 2013), as well as with other quantificational constructions, such as $P$ in every respect, some respect, and most respects. Nouns and adjectives of additional domains can be tested (for instance, abstract nouns: problem, love), as well as additive natural kind nouns and multiplicative social nouns, assuming such exist. The role of mediating particles (cf., of in (3a)) should also be addressed.

The present study has broader implications for our understanding of the adjective-noun word class distinction, including in particular 'nouny' adjectives and adjective-like nouns. Consider in particular, nationality concepts such as American 
or trait concepts such as extrovert. They can fill in attributive-adjective positions as in extrovert personality and American nationality, but unlike most adjectives, they can also 'stand alone' in argument positions without any explicit noun around, as in Americans and extroverts, and unlike the ill-formed \#talls and \#healthies. An explanation in terms of categorization based on accessible dimensions deserves consideration. Possibly, in argument position, the dimensions are bound by additive similarity functions, with equal dimensional weights. But since this type of interpretation can be represented by means of a dimension set bound by a quantifier, these nouns easily occupy adjectival positions.

Additional implications pertain to size adjectives such as big and huge. When modifying certain nouns, as in this midget is a big fan, they do not attribute big physical size. Morzycki (2009) argues that this interpretation of big occurs when it modifies a noun that is itself morphologically gradable (e.g., fan, stamp-collector, genius or idiot). For example, smoker denotes a measurement of frequency or affinity for smoking. On this view, size adjectives function as degree modifiers, similar to very (type $<\mathrm{d}, \mathrm{t}>$ ); e.g., big denotes a mapping $\mathrm{f}_{\mathrm{big}}$ of nominal degrees $\mathrm{d}$ to their relative size, $\mathrm{f}_{\text {big }}(\mathrm{d})$. Morzycki further observes that nominal gradability readings of size adjectives are absent in predicate position (as in the fan is big), or in negative size adjectives (as in a small fan just came in, which relates to physical size, not fan-hood). These features are unique to nominal-gradability readings, as opposed to abstract size readings (as in this mistake is big/small) and significance readings (he is huge!). The position generalization is captured by postulating a morpheme meas in the nominal degree projection, which is not available in other positions. Meas takes as arguments a gradable noun, a size adjective, and an entity and returns truth if and only if the entity falls under the noun and its degree in the noun is big.

However, this account of gradable nouns in terms of degree functions fails to explain why these nouns are not generally compatible with gradability morphemes (e.g., *faner, *fanest, *too fan), and why their combinations with more must be mediated, as in more of an idiot than Bill. The results reported in this paper give rise to an alternative approach, which rests on the observation that the gradable dimensions of adjectives are often context dependent, and their choice is affected, among other things, by the noun they modify. For example, the dimension of long is different for tables than for stories. Assuming that nouns are themselves associated with dimension sets, size adjectives may, under certain circumstances, be able to access and operate on these sets. The position generalization can be captured by postulating that, unless an adjective has a dimension set argument (as typical does in, e.g., typical of birds), only in attributive position can it access the dimension set of the noun it modifies (perhaps by virtue of a syntactic head whose semantics does the job). This account uses Morzycki's logic, but spares the need to stipulate that some nouns denote a degree function, while most other nouns do not, or that size adjectives are adverbial (adnominal) modifiers, while most other adjectives are not.

This approach extends beyond size adjectives and explains the different interpretations of old in He is an old friend and This friend is old. Thus, the availability of nominal dimensions for adjectives to operate on is a more general phenomenon in attributive position. Moreover, the set of examples of gradable nouns reported in 
the literature typically includes nouns such as idiot, nerd, soccer fan, airhead, goat cheese enthusiast, simpleton, Barbie doll lover, loser, and weirdo (de Vries 2010). It is easy to observe that all of them belong to the social domain. Thus, their dimensions are expected to be relatively accessible for grammatical operations to quantify over as in idiot with respect to his political views and completeltotal idiot (de Vries 2010). Moreover, these nouns seem to have morphologically gradable dimensions (e.g., stupid, intelligent, admiring) accessible for size adjectives to select and use for their interpretation.

Dimension accessibility for quantifier binding seems to affect additional gradable constructions. For example, in various languages human categories such as boy and girl directly combine with the modifier very, as in the Hebrew meod yalada ("very girl', 'very girlish/immature') and Spanish Es muy hombre ('is very man', 'He is very much a man'; Espinal 2013). Additive dimension binding for the noun girl makes its dimensions more accessible than those of most other nouns. The importance of gradable traits in the stereotype of girls (e.g., loving pink) can be stretched to the point that girl is interpreted as equivalent to girlish, thereby licensing very. In sum, nouns carrying expressive or evaluative components such as idiot, coward, hero or child in its metaphoric sense, get as close to gradable adjectives as nouns can (Constantinescu 2011: 49-96), perhaps because they have adjectival dimensions (another point to consider in the future).

To conclude, the main result of the reported study is a connection between the acceptability of a given noun or adjective in comparison constructions and its type of characteristic categorization criterion (i.e., whether, as a default, its dimensions combine into a single criterion via quantifiers or other operations). This result highlights connections between cognitive psychological findings and linguistic phenomena, thus potentially contributing to the study of morphological gradability within linguistics and to an improved understanding of certain experimental results in cognitive psychology, where the potential role of the noun-adjective distinction was overlooked (Wattenmaker 1995). By raising awareness both to grammatical and conceptual distinctions, and by pointing out directions for future research, this paper has aimed to deepen our understanding of the relations between the formal and conceptual components of natural languages.

Acknowledgements Many thanks for the financial support by a Grant from the GIF, the German-Israeli Foundation for Scientific Research and Development. Special thanks also to the editors, James Hampton and Yoad Winter, for the inspiring workshop and very useful comments. 


\section{Appendix A: Averages on 25 Participants for the Compar- ison Conditions with Nouns (Left) and Adjectives (Right)}

\begin{tabular}{|c|c|c|c|c|c|c|c|c|c|}
\hline \multirow{3}{*}{$\begin{array}{l}\text { Nominal } \\
\text { predicates by } \\
\text { entity type }\end{array}$} & \multirow{2}{*}{\multicolumn{2}{|c|}{$\begin{array}{l}\text { Single subject } \\
\text { between-noun } \\
\text { comparisons }\end{array}$}} & \multirow{2}{*}{\multicolumn{2}{|c|}{$\begin{array}{l}\text { Within-noun } \\
\text { comparisons }\end{array}$}} & \multirow{2}{*}{\multicolumn{2}{|c|}{$\begin{array}{l}\text { Two-subject } \\
\text { between-noun } \\
\text { comparisons } \\
\text { More NP }{ }^{1} \\
\text { than y is } \mathrm{NP}^{2}\end{array}$}} & \multirow{3}{*}{$\begin{array}{l}\text { Adjectival } \\
\text { predicates by } \\
\text { entity type }\end{array}$} & \multirow{2}{*}{\multicolumn{2}{|c|}{$\begin{array}{l}\text { Within- } \\
\text { adjective } \\
\text { comparisons }\end{array}$}} \\
\hline & & & & & & & & & \\
\hline & M & SD & M & SD & M & SD & & M & SD \\
\hline Cow & 3.64 & 2.06 & 2.92 & 2.00 & 2.32 & 1.62 & Taller & 5.88 & 1.56 \\
\hline Mosquito & 2.64 & 1.94 & 2.68 & 1.76 & 2.52 & 1.70 & Bigger & 6.84 & 0.61 \\
\hline Crow & 2.68 & 2.03 & 2.16 & 1.54 & 1.96 & 1.37 & More expensive & 6.32 & 1.12 \\
\hline Snake & 4.84 & 1.93 & 3.6 & 1.70 & 3.16 & 2.13 & More colorful & 6.72 & 0.60 \\
\hline Tiger & 4.28 & 2.03 & 3.28 & 1.80 & 2.84 & 1.69 & Heavier & 5.6 & 1.74 \\
\hline Dolphin & 3.6 & 2.15 & 2.8 & 1.74 & 2.56 & 1.24 & Older & 5.48 & 2.14 \\
\hline Plants & & & & & & & Plants & & \\
\hline Pine & 4.52 & 1.96 & 4.32 & 1.93 & 3.28 & 1.93 & Older & 5.84 & 1.83 \\
\hline Potato & 3.16 & 2.19 & 2.12 & 1.45 & 2.2 & 1.50 & Bigger & 6.4 & 0.94 \\
\hline Dandelion & 3.72 & 1.97 & 4.08 & 2.00 & 2.8 & 1.60 & More expensive & 6.08 & 1.65 \\
\hline Mint & 3.32 & 1.89 & 3.76 & 1.94 & 2.52 & 1.65 & More colorful & 6.72 & 0.72 \\
\hline Moss & 4.76 & 1.97 & 3.52 & 1.90 & 3.4 & 1.79 & Taller & 5.68 & 1.76 \\
\hline Orange & 3.6 & 2.00 & 3.4 & 2.23 & 2.48 & 1.58 & Heavier & 6.4 & 1.39 \\
\hline Artifacts & & & & & & & Artifacts & & \\
\hline Church & 5.48 & 1.60 & 4.48 & 1.90 & 4.24 & 2.06 & Older & 6.16 & 1.59 \\
\hline Dress & 5.44 & 1.63 & 3.8 & 2.15 & 2.8 & 1.83 & More colorful & 6 & 1.52 \\
\hline Taxi & 3.72 & 2.20 & 4 & 1.94 & 2.92 & 1.65 & Heavier & 5.88 & 1.70 \\
\hline Theatre & 5.04 & 2.05 & 4.08 & 2.26 & 3.44 & 1.83 & Bigger & 6.6 & 0.69 \\
\hline Vase & 5.76 & 1.75 & 4.32 & 1.69 & 3.16 & 1.87 & Taller & 6.24 & 1.14 \\
\hline Diary & 6.2 & 1.26 & 4.44 & 1.92 & 3.32 & 1.93 & More expensive & 6.64 & 1.02 \\
\hline Humans & & & & & & & Humans & & \\
\hline Reporter & 5.48 & 1.50 & 4.12 & 1.99 & 2.96 & 1.71 & Older & 5.4 & 1.85 \\
\hline Composer & 5.76 & 1.36 & 4.76 & 2.03 & 3.12 & 1.68 & More colorful & 5.68 & 1.64 \\
\hline Champion & 5.44 & 1.36 & 4.76 & 1.77 & 3.56 & 1.83 & More expensive & 4.68 & 2.26 \\
\hline Genius & 4.32 & 2.22 & 5.24 & 1.75 & 2.12 & 1.53 & Bigger & 6.6 & 0.94 \\
\hline Businesswoman & 4.88 & 1.92 & 4.32 & 1.87 & 3.16 & 1.97 & Heavier & 5.56 & 1.55 \\
\hline Person & 5.2 & 2.14 & 5.2 & 2.04 & 3 & 2.02 & Taller & 6.8 & 0.63 \\
\hline M & 4.48 & 1.03 & 3.84 & 0.86 & 2.91 & 0.52 & $\mathbf{M}$ & 6.09 & 0.54 \\
\hline SD & 1.03 & 0.28 & 0.86 & 0.20 & 0.52 & 0.22 & SD & 0.54 & 0.50 \\
\hline
\end{tabular}




\section{Appendix B: Averages on 25 Participants for the 24 Nouns in Baseline and Modified Conditions}

\begin{tabular}{|c|c|c|c|c|c|c|c|c|c|}
\hline \multirow[b]{3}{*}{ Entity type } & \multirow[b]{3}{*}{ Item Noun } & \multirow{2}{*}{\multicolumn{2}{|c|}{$\begin{array}{l}\text { Basic } \\
\text { categorization } \\
\text { conditions } \\
\text { (Pos) } \\
\mathrm{X} \text { is NP }\end{array}$}} & \multirow{2}{*}{\multicolumn{2}{|c|}{$\begin{array}{l}\text { Negated } \\
\text { categorization } \\
\text { conditions } \\
\text { (Not) } \\
\text { X is not NP }\end{array}$}} & \multirow{2}{*}{\multicolumn{2}{|c|}{$\begin{array}{l}\text { Exception } \\
\text { phrase } \\
\text { condition }(\mathrm{Ex})\end{array}$}} & \multirow{2}{*}{\multicolumn{2}{|c|}{$\begin{array}{l}\text { Negated } \\
\text { exception } \\
\text { phrase } \\
\text { condition } \\
\text { (ExNot) } \\
\text { X is not NP } \\
\text { except }\end{array}$}} \\
\hline & & & & & & & & & \\
\hline & & M & SD & M & SD & M & SD & M & SD \\
\hline \multirow[t]{6}{*}{ Animals } & Cow & 6.68 & 1.12 & 6.68 & 0.68 & 1.92 & 1.29 & 2.04 & 1.40 \\
\hline & Mosquito & 3.48 & 2.44 & 5 & 2.43 & 2.24 & 1.70 & 2.88 & 1.90 \\
\hline & Crow & 3.04 & 2.51 & 3.44 & 2.56 & 1.8 & 1.30 & 1.68 & 1.41 \\
\hline & Snake & 6.72 & 0.87 & 6.64 & 1.23 & 3.64 & 2.31 & 4 & 1.94 \\
\hline & Tiger & 6.52 & 1.06 & 6.76 & 0.65 & 2.32 & 1.49 & 1.96 & 1.31 \\
\hline & Dolphin & 6.68 & 0.68 & 6.36 & 1.23 & 3.08 & 1.79 & 3.52 & 1.96 \\
\hline \multirow[t]{6}{*}{ Plants } & Pine & 6.64 & 1.09 & 6.76 & 0.59 & 2.84 & 1.38 & 2.64 & 1.57 \\
\hline & Potato & 6.64 & 0.93 & 6.32 & 1.64 & 2.88 & 1.99 & 2 & 1.50 \\
\hline & Dandelion & 6.84 & 0.46 & 6.92 & 0.39 & 3.28 & 2.16 & 2.68 & 1.67 \\
\hline & Mint & 5.12 & 1.88 & 5.12 & 2.16 & 3.12 & 2.10 & 2.52 & 1.53 \\
\hline & Moss & 5.92 & 1.92 & 6.72 & 0.72 & 2.48 & 1.86 & 2.76 & 2.12 \\
\hline & Orange & 6.68 & 0.88 & 6.64 & 0.79 & 3.04 & 1.93 & 2.48 & 1.68 \\
\hline \multirow[t]{6}{*}{ Artifacts } & Church & 6.92 & 0.27 & 6.72 & 0.66 & 4.32 & 2.48 & 5.24 & 2.34 \\
\hline & Dress & 6.72 & 0.60 & 6.84 & 0.54 & 2.88 & 1.88 & 2.84 & 2.07 \\
\hline & Taxi & 6.52 & 1.02 & 6.84 & 0.54 & 3.24 & 1.94 & 3.48 & 1.94 \\
\hline & Theatre & 6.12 & 1.77 & 6.12 & 1.68 & 4.32 & 2.11 & 3.64 & 2.02 \\
\hline & Vase & 6.72 & 0.66 & 6.52 & 1.30 & 3.04 & 1.78 & 2.16 & 1.57 \\
\hline & Diary & 6.16 & 1.01 & 6.92 & 0.27 & 4.08 & 1.74 & 3.56 & 2.14 \\
\hline \multirow[t]{8}{*}{ Humans } & Reporter & 6.6 & 1.10 & 6 & 1.62 & 2.56 & 1.88 & 2.4 & 1.50 \\
\hline & Composer & 6.8 & 0.63 & 6.84 & 0.61 & 2.72 & 1.89 & 3.84 & 2.22 \\
\hline & Champion & 7 & 0.00 & 6.76 & 0.59 & 4.28 & 1.76 & 4.28 & 1.84 \\
\hline & Genius & 6.84 & 0.61 & 6.88 & 0.43 & 5.04 & 1.99 & 5.16 & 1.57 \\
\hline & Businesswoman & 5.72 & 1.25 & 5.16 & 1.87 & 3.08 & 1.57 & 2.76 & 1.53 \\
\hline & Person & 6.8 & 0.80 & 6.84 & 0.46 & 2.56 & 1.90 & 3.08 & 1.81 \\
\hline & $\mathbf{M}$ & 6.25 & 1.07 & 6.32 & 1.07 & 3.11 & 0.81 & 3.07 & 0.95 \\
\hline & SD & 1.02 & 0.63 & 0.84 & 0.69 & 0.81 & 0.29 & 0.95 & 0.29 \\
\hline
\end{tabular}




\section{Appendix C: The Full Set of Sentences Together with Their Naturalness Mean and Sd}

\begin{tabular}{|c|c|c|c|}
\hline Item & Structure: basic form & Mean & $\underline{\text { Std }}$ \\
\hline 1. & [BaA1] This farm animal is a cow & 6.68 & 1.12 \\
\hline 2. & [BaA2] This fly is a mosquito & 3.48 & 2.44 \\
\hline 3. & [BaA3] This bird is a crew & 3.04 & 2.51 \\
\hline 4. & [BaA4] This reptile is a snake & 6.72 & 0.87 \\
\hline 5. & [BaA5] This predator is a tiger & 6.52 & 1.06 \\
\hline 6. & [BaA6] This aquatic mammal is a dolphin & 6.68 & 0.68 \\
\hline 7. & [BaH1] This journalist is a reporter & 6.6 & 1.10 \\
\hline 8. & [BaH2] This artist is a composer & 6.8 & 0.63 \\
\hline 9. & [BaH3] This football player is a champion & 7 & 0.00 \\
\hline 10. & {$[\mathrm{BaH} 4]$ This girl is a genius } & 6.84 & 0.61 \\
\hline 11. & [BaH5] This colleague is a businesswoman & 5.72 & 1.25 \\
\hline 12. & [BaH6] This person is a victim & 6.8 & 0.80 \\
\hline 13. & {$[\mathrm{BaP} 1]$ This tree is a pine } & 6.64 & 1.09 \\
\hline 14. & [BaP2] This vegetable is a potato & 6.64 & 0.93 \\
\hline 15. & [BaP3] This flower is a dandelion & 6.84 & 0.46 \\
\hline 16. & [BaP4] This spice is a mint & 5.12 & 1.88 \\
\hline 17. & [BaP5] This plant is moss & 5.92 & 1.92 \\
\hline 18. & [BaP6] This piece of fruit is an orange & 6.68 & 0.88 \\
\hline 19. & [BaT1] This place is a church & 6.92 & 0.27 \\
\hline 20. & [BaT2] This piece of clothing is a dress & 6.72 & 0.60 \\
\hline 21. & [BaT3] This car is a taxi & 6.52 & 1.02 \\
\hline 22. & [BaT4] This hall is a theatre & 6.12 & 1.77 \\
\hline 23. & [BaT5] This container is a vase & 6.72 & 0.66 \\
\hline \multirow[t]{2}{*}{24.} & [BaT6] This booklet is a diary & 6.16 & 1.01 \\
\hline & Structure: Negated Basic form & $6.25(1.02)$ & $1.07(0.63)$ \\
\hline 1. & $\overline{\text { [BaNA1] }}$ This farm animal is not a cow & 6.68 & 0.68 \\
\hline 2. & [BaNA2] This fly is not a mosquito & 5 & 2.43 \\
\hline 3. & [BaNA3] This bird is not a crew & 3.44 & 2.56 \\
\hline 4. & [BaNA4] This reptile is not a snake & 6.64 & 1.23 \\
\hline 5. & [BaNA5] This predator is not a tiger & 6.76 & 0.65 \\
\hline 6. & [BaNA6] This aquatic mammal is not a dolphin & 6.36 & 1.23 \\
\hline 7. & [BaNH1] This journalist is not a reporter & 6 & 1.62 \\
\hline 8. & [BaNH2] This artist is not a composer & 6.84 & 0.61 \\
\hline 9. & [BaNH3] This football player is not a champion & 6.76 & 0.59 \\
\hline 10. & [BaNH4] This girl is not a genius & 6.88 & 0.43 \\
\hline 11. & [BaNH5] This colleague is not a businesswoman & 5.16 & 1.87 \\
\hline 12. & [BaNH6] This person is not a victim & 6.84 & 0.46 \\
\hline 13. & [BaNP1] This tree is not a pine & 6.76 & 0.59 \\
\hline 14. & [BaNP2] This vegetable is not a potato & 6.32 & 1.64 \\
\hline
\end{tabular}


(continued)

\begin{tabular}{|c|c|c|c|}
\hline Item & Structure: basic form & Mean & Std \\
\hline 15. & [BaNP3] This flower is not a dandelion & 6.92 & 0.39 \\
\hline 16. & [BaNP4] This spice is not a mint & 5.12 & 2.16 \\
\hline 17. & [BaNP5] This plant is not moss & 6.72 & 0.72 \\
\hline 18. & [BaNP6] This piece of fruit is not an orange & 6.64 & 0.79 \\
\hline 19. & [BaNT1] This place is not a church & 6.72 & 0.66 \\
\hline 20. & [BaNT2] This piece of clothing is not a dress & 6.84 & 0.54 \\
\hline 21. & [BaNT3] This car is not a taxi & 6.84 & 0.54 \\
\hline 22. & [BaNT4] This hall is not a theatre & 6.12 & 1.68 \\
\hline 23. & [BaNT5] This container is not a vase & 6.52 & 1.30 \\
\hline \multirow[t]{2}{*}{24.} & [BaNT6] This booklet is not a diary & 6.92 & 0.27 \\
\hline & $\underline{\text { Structure: }}$ Single entity Between noun comparisons & $6.32(0.84)$ & $1.07(0.07)$ \\
\hline 1. & [Be1s1A1] This farm animal is more a cow than a horse & 3.64 & 2.06 \\
\hline 2. & [Be1s1A2] This fly is more a mosquito than a wasp & 2.64 & 1.94 \\
\hline 3. & [Be1s1A3] This bird is more a crew than a pigeon & 2.68 & 2.03 \\
\hline 4. & [Be1s1A4] This reptile is more a snake than a lizard & 4.84 & 1.93 \\
\hline 5. & [Be1s1A5] This predator is more a wolf than a tiger & 4.28 & 2.03 \\
\hline 6. & [Be1s1A6] This aquatic mammal is more a dolphin than a shark & 3.6 & 2.15 \\
\hline 7. & [Be1sP1] This tree is more a pine than an oak & 4.52 & 1.96 \\
\hline 8. & [Be1sP2] This vegetable is more a potato than a carrot & 3.16 & 2.19 \\
\hline 9. & [Be1sP3] This flower is more a dandelion than a rose & 3.72 & 1.97 \\
\hline 10. & [Be1sP4] This spice is more onion than mint & 3.32 & 1.89 \\
\hline 11. & [Be1sP5] This plant is more moss than grass & 4.76 & 1.97 \\
\hline 12. & [Be1sP6] This piece of fruit is more an orange than an apple & 3.6 & 2.00 \\
\hline 13. & [Be1sT1] This place is more a church than an art gallery & 5.48 & 1.60 \\
\hline 14. & [Be1sT2] This piece of clothing is more a dress than a nightshirt & 5.44 & 1.63 \\
\hline 15. & [Be1sT3] This car is more a taxi than an ambulance & 3.72 & 2.20 \\
\hline 16. & [Be1sT4] This hall is more a theatre than a cinema & 5.04 & 2.05 \\
\hline 17. & [Be1sT5] This container is more a carafe than a vase & 5.76 & 1.75 \\
\hline 18. & [Be1sT6] This booklet is more a diary than a sketchbook & 6.2 & 1.26 \\
\hline 19. & [Be1sH1] This journalist is more a consultant than a reporter & 5.48 & 1.50 \\
\hline 20. & [Be1sH2] This artist is more a composer than a poet & 5.76 & 1.36 \\
\hline 21. & [Be1sH3] This football player is more a champion than a celebrity & 5.44 & 1.36 \\
\hline 22. & [Be1sH4] This girl is more a genius than a child & 4.32 & 2.22 \\
\hline 23. & [Be1sH5] This colleague is more a businesswoman than a friend & 4.88 & 1.92 \\
\hline \multirow[t]{2}{*}{24.} & [Be1sH6] This person is more a victim than a witness & 5.2 & 2.14 \\
\hline & Structure: Two entity Between noun comparisons & $4.48(1.03)$ & $1.03(0.28)$ \\
\hline 1. & $\begin{array}{l}\text { [Be2sA1] This farm animal is more a cow than that farm animal is a } \\
\text { horse }\end{array}$ & 2.32 & 1.62 \\
\hline 2. & [Be2sA2] This fly is more a mosquito than that fly is a wasp & 2.52 & 1.70 \\
\hline 3. & [Be2sA3] This bird is more a crew than that bird is a pigeon & 1.96 & 1.37 \\
\hline 4. & [Be2sA4] This reptile is more a snake than that reptile is a lizard & 3.16 & 2.13 \\
\hline 5. & [Be2sA5] This predator is more a wolf than that predator is a tiger & 2.84 & 1.69 \\
\hline
\end{tabular}


(continued)

\begin{tabular}{|c|c|c|c|}
\hline Item & Structure: basic form & Mean & Std \\
\hline 6. & $\begin{array}{l}\text { [Be2sA6] This aquatic mammal is more a dolphin than that aquatic } \\
\text { mammal is a shark }\end{array}$ & 2.56 & 1.24 \\
\hline 7. & [Be2sP1] This tree is more a pine than that tree is an oak & 3.28 & 1.93 \\
\hline 8. & [Be2sP2] This vegetable is more a potato than that vegetable a carrot & 2.2 & 1.50 \\
\hline 9. & [Be2sP3] This flower is more a dandelion than that flower is a rose & 2.8 & 1.60 \\
\hline 10. & [Be2sP4] This spice is more onion than that spice is a mint & 2.52 & 1.65 \\
\hline 11. & [Be2sP5] This plant is more moss than that plant is grass & 3.4 & 1.79 \\
\hline 12. & $\begin{array}{l}\text { [Be2sP6] This piece of fruit is more an orange than that piece of fruit is } \\
\text { an apple }\end{array}$ & 2.48 & 1.58 \\
\hline 13. & [Be2sT1] This place is more a church than that place is an art gallery & 4.24 & 2.06 \\
\hline 14. & $\begin{array}{l}\text { [Be2sT2] This piece of clothing is more a dress than that piece of } \\
\text { clothing is a nightshirt }\end{array}$ & 2.8 & 1.83 \\
\hline 15. & [Be2sT3] This car is more a taxi than that car is an ambulance & 2.92 & 1.65 \\
\hline 16. & [Be2sT4] This hall is more a theatre than that hall is a cinema & 3.44 & 1.83 \\
\hline 17. & [Be2sT5] This container is more a carafe than that container is a vase & 3.16 & 1.87 \\
\hline 18. & [Be2sT6] This booklet is more a diary than that booklet is a sketchbook & 3.32 & 1.93 \\
\hline 19. & $\begin{array}{l}\text { [Be2sH1] This journalist is more a consultant than that journalist is a } \\
\text { reporter }\end{array}$ & 2.96 & 1.71 \\
\hline 20. & [Be2sH2] This artist is more a composer than that artists is a poet & 3.12 & 1.68 \\
\hline 21. & $\begin{array}{l}\text { [Be2sH3] This football player is more a champion than that football } \\
\text { player is a celebrity }\end{array}$ & 3.56 & 1.83 \\
\hline 22. & [Be2sH4] This girl is more a genius than that girl is a child & 2.12 & 1.53 \\
\hline 23. & $\begin{array}{l}\text { [Be2sH5] This colleague is more a businesswoman than that colleague is } \\
\text { a friend }\end{array}$ & 3.16 & 1.97 \\
\hline \multirow[t]{2}{*}{24.} & [Be2sH6] This person is more a victim than that person is a witness & 3 & 2.02 \\
\hline & $\underline{\text { Structure: Within adjective comparison }}$ & $2.91(0.52)$ & $0.52(0.22)$ \\
\hline 25. & [WaA1] This farm animal is taller than that farm animal is & 5.88 & 1.56 \\
\hline 26. & [WaA2] This fly is bigger than that fly & 6.84 & 0.61 \\
\hline 27. & [WaA3] This bird is more expensive than that bird is & 6.32 & 1.12 \\
\hline 28. & [WaA4] This reptile is more colorful than that reptile & 6.72 & 0.60 \\
\hline 29. & [WaA5] This predator is heavier than that predator is & 5.6 & 1.74 \\
\hline 30. & [WaA6] This aquatic mammal is older than that aquatic mammal & 5.48 & 2.14 \\
\hline 31. & [WaP1] This tree is older than that tree is & 5.84 & 1.83 \\
\hline 32. & [WaP2] This vegetable is bigger than that vegetable & 6.4 & 0.94 \\
\hline 33. & [WaP3] This flower is more expensive than that flower is & 6.08 & 1.65 \\
\hline 34. & [WaP4] This spice is more colorful than that spice & 6.72 & 0.72 \\
\hline 35. & [WaP5] This plant is taller than that plant is & 5.68 & 1.76 \\
\hline 36. & [WaP6] This piece of fruit is heavier than that piece of fruit & 6.4 & 1.39 \\
\hline 37. & [WaT1] This place is older than that place is & 6.16 & 1.59 \\
\hline
\end{tabular}


(continued)

\begin{tabular}{|c|c|c|c|}
\hline Item & Structure: basic form & Mean & $\underline{\text { Std }}$ \\
\hline 38. & $\begin{array}{l}\text { [WaT2] This piece of clothing is more colorful than that piece of } \\
\text { clothing }\end{array}$ & 6 & 1.52 \\
\hline 39. & [WaT3] This car is heavier than that car is & 5.88 & 1.70 \\
\hline 40. & [WaT4] This hall is bigger than that hall & 6.6 & 0.69 \\
\hline 41. & [WaT5] This container is taller than that container is & 6.24 & 1.14 \\
\hline 42. & [WaT6] This booklet is more expensive than that booklet & 6.64 & 1.02 \\
\hline 43. & [WaH1] This journalist is older than that journalist is & 5.4 & 1.85 \\
\hline 44. & [WaH2] This artist is more colorful than that artist & 5.68 & 1.64 \\
\hline 45. & $\begin{array}{l}\text { [WaH3] This football player is more expensive than that football player } \\
\text { is }\end{array}$ & 4.68 & 2.26 \\
\hline 46. & [WaH4] This girl is bigger than that girl & 6.6 & 0.94 \\
\hline 47. & [WaH5] This colleague is heavier than that colleague is & 5.56 & 1.55 \\
\hline \multirow[t]{2}{*}{48.} & [WaH6] This person is taller than that person & 6.8 & 0.63 \\
\hline & Structure: Within noun comparisons & $6.09(0.54)$ & $0.54(0.50)$ \\
\hline 1. & [WhA1] This farm animal is more a cow than that farm animal is & 2.92 & 2.00 \\
\hline 2. & [WhA2] This fly is more a mosquito than that fly & 2.68 & 1.76 \\
\hline 3. & [WhA3] This bird is more a crew than that bird is & 2.16 & 1.54 \\
\hline 4. & [WhA4] This reptile is more a snake than that reptile & 3.6 & 1.70 \\
\hline 5. & [WhA5] This predator is more a tiger than that predator is & 3.28 & 1.80 \\
\hline 6. & $\begin{array}{l}\text { [WhA6] This aquatic mammal is more a dolphin than that aquatic } \\
\text { mammal }\end{array}$ & 2.8 & 1.74 \\
\hline 7. & [WhP1] This tree is more a pine than that tree is & 4.32 & 1.93 \\
\hline 8. & [WhP2] This vegetable is more a potato than that vegetable & 2.12 & 1.45 \\
\hline 9. & [WhP3] This flower is more a dandelion than that flower is & 4.08 & 2.00 \\
\hline 10. & [WhP4] This spice is more a mint than that spice & 3.76 & 1.94 \\
\hline 11. & [WhP5] This plant is more moss than that plant is & 3.52 & 1.90 \\
\hline 12. & [WhP6] This piece of fruit is more an orange than that piece of fruit & 3.4 & 2.23 \\
\hline 13. & [WhT1] This place is more a church than that place is & 4.48 & 1.90 \\
\hline 14. & [WhT2] This piece of clothing is more a dress than that piece of clothing & 3.8 & 2.15 \\
\hline 15. & [WhT3] This car is more a taxi than that car is & 4 & 1.94 \\
\hline 16. & [WhT4] This hall is more a theatre than that hall & 4.08 & 2.26 \\
\hline 17. & [WhT5] This container is more a vase than that container is & 4.32 & 1.69 \\
\hline 18. & [WhT6] This booklet is more a diary than that booklet & 4.44 & 1.92 \\
\hline 19. & [WhH1] This journalist is more a reporter than that journalist is & 4.12 & 1.99 \\
\hline 20. & [WhH2] This artist is more a composer than that artist & 4.76 & 2.03 \\
\hline 21. & $\begin{array}{l}\text { [WhH3] This football player is more a champion than that football } \\
\text { player is }\end{array}$ & 4.76 & 1.77 \\
\hline 22. & [WhH4] This girl is more a genius than that girl & 5.24 & 1.75 \\
\hline 23. & [WhH5] This colleague is more a businesswoman than that colleague is & 4.32 & 1.87 \\
\hline 24. & [WhH6] This person is more a victim than that person & 5.2 & 2.04 \\
\hline
\end{tabular}


(continued)

\begin{tabular}{|c|c|c|c|}
\hline Item & Structure: basic form & Mean & $\underline{\text { Std }}$ \\
\hline & 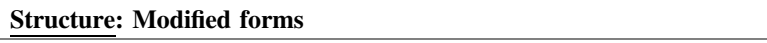 & $3.84(0.86)$ & $0.86(0.20)$ \\
\hline 1. & [ExA1] This farm animal is a cow except for its milk taste & 1.92 & 1.29 \\
\hline 2. & $\begin{array}{l}\text { [ExA2] This fly is a mosquito except with respect to the chemistry of its } \\
\text { blood }\end{array}$ & 2.24 & 1.70 \\
\hline 3. & [ExA3] This bird is a crew except for its eating habits & 1.8 & 1.30 \\
\hline 4. & [ExA4] This reptile is a snake except with respect to eye structure & 3.64 & 2.31 \\
\hline 5. & [ExA5] This predator is a tiger except for its teeth number & 2.32 & 1.49 \\
\hline 6. & [ExA6] This aquatic mammal is a dolphin except in behavior & 3.08 & 1.79 \\
\hline 7. & [ExP1] This tree is a pine except with respect to the wood fibers & 2.84 & 1.38 \\
\hline 8. & [ExP2] This vegetable is a potato except for color & 2.88 & 1.99 \\
\hline 9. & [ExP3] This flower is a dandelion except in size & 3.28 & 2.16 \\
\hline 10. & [ExP4] This spice is a mint except for the bitterness & 3.12 & 2.10 \\
\hline 11. & [ExP5] This plant is moss except with respect to metabolism & 2.48 & 1.86 \\
\hline 12. & [ExP6] This piece of fruit is an orange except for shape & 3.04 & 1.93 \\
\hline 13. & [ExT1] This place is a church except in appearance & 4.32 & 2.48 \\
\hline 14. & [ExT2] This piece of clothing is a dress except for its use & 2.88 & 1.88 \\
\hline 15. & [ExT3] This car is a taxi except for its current function & 3.24 & 1.94 \\
\hline 16. & [ExT4] This hall is a theatre except with respect to seat type & 4.32 & 2.11 \\
\hline 17. & [ExT5] This container is a vase except with respect to texture & 3.04 & 1.78 \\
\hline 18. & [ExT6] This booklet is a diary except for the sketches & 4.08 & 1.74 \\
\hline 19. & [ExH1] This journalist is a reporter except for salary & 2.56 & 1.88 \\
\hline 20. & [ExH2] This artist is a composer except with respect to education & 2.72 & 1.89 \\
\hline 21. & [ExH3] This football player is a champion except for running abilities & 4.28 & 1.76 \\
\hline 22. & [ExH4] This girl is a genius except with respect to literature. & 5.04 & 1.99 \\
\hline 23. & [ExH5] This colleague is a businesswoman except in generosity. & 3.08 & 1.57 \\
\hline \multirow[t]{2}{*}{24.} & [ExH6] This person is a victim except for subjective experience & 2.56 & 1.90 \\
\hline & Structure: Negated modified forms & $3.11(0.81)$ & $0.81(0.29)$ \\
\hline 1. & [ExNA1] This farm animal is not a cow except for its milk taste & 2.04 & 1.40 \\
\hline 2. & $\begin{array}{l}\text { [ExNA2] This fly is not a mosquito except with respect to the chemistry } \\
\text { of its blood }\end{array}$ & 2.88 & 1.90 \\
\hline 3. & [ExNA3] This bird is not a crew except for its eating habits & 1.68 & 1.41 \\
\hline 4. & [ExNA4] This reptile is not a snake except with respect to eye structure & 4 & 1.94 \\
\hline 5. & [ExNA5] This predator is not a tiger except for its teeth number & 1.96 & 1.31 \\
\hline 6. & [ExNA6] This aquatic mammal is not a dolphin except in behavior & 3.52 & 1.96 \\
\hline 7. & [ExNP1] This tree is not a pine except with respect to the wood fibers & 2.64 & 1.57 \\
\hline 8. & [ExNP2] This vegetable is not a potato except for color & 2 & 1.50 \\
\hline 9. & [ExNP3] This flower is not a dandelion except in size & 2.68 & 1.67 \\
\hline 10. & [ExNP4] This spice is not a mint except for the bitterness & 2.52 & 1.53 \\
\hline
\end{tabular}


(continued)

\begin{tabular}{|c|c|c|c|}
\hline Item & Structure: basic form & Mean & $\underline{\text { Std }}$ \\
\hline 11. & [ExNP5] This plant is not moss except with respect to metabolism & 2.76 & 2.12 \\
\hline 12. & [ExNP6] This piece of fruit is not an orange except for shape & 2.48 & 1.68 \\
\hline 13. & [ExNT1] This place is not a church except in appearance & 5.24 & 2.34 \\
\hline 14. & [ExNT2] This piece of clothing is not a dress except for its use & 2.84 & 2.07 \\
\hline 15. & [ExNT3] This car is not a taxi except for its current function & 3.48 & 1.94 \\
\hline 16. & [ExNT4] This hall is not a theatre except with respect to seat type & 3.64 & 2.02 \\
\hline 17. & [ExNT5] This container is not a vase except with respect to texture & 2.16 & 1.57 \\
\hline 18. & [ExNT6] This booklet is not a diary except for the sketches & 3.56 & 2.14 \\
\hline 19. & [ExNH1] This journalist is not a reporter except for salary & 2.4 & 1.50 \\
\hline 20. & [ExNH2] This artist is not a composer except with respect to education & 3.84 & 2.22 \\
\hline 21. & $\begin{array}{l}\text { [ExNH3] This football player is not a champion except for running } \\
\text { abilities }\end{array}$ & 4.28 & 1.84 \\
\hline 22. & [ExNH4] This girl is not a genius except with respect to literature. & 5.16 & 1.57 \\
\hline 23. & [ExNH5] This colleague is not a businesswoman except in generosity. & 2.76 & 1.53 \\
\hline \multirow[t]{2}{*}{24.} & [ExNH6] This person is not a victim except for subjective experience & 3.08 & 1.81 \\
\hline & Fillers & $3.07(0.95)$ & $0.95(0.29)$ \\
\hline 1. & [Filba] This chair is often wide & 2.28 & 2.01 \\
\hline 2. & [Filba] This inspector saw anything & 1.96 & 1.46 \\
\hline 3. & [Filgo] This inspector did not see anything & 6.8 & 0.63 \\
\hline 4. & [Filgo] This chair is often covered & 6.16 & 1.29 \\
\hline 5. & {$[\mathrm{HeBa}]$ This boy is healthy } & 6.88 & 0.43 \\
\hline 6. & {$[\mathrm{HeEx}]$ This boy is healthy except for a cold } & 4.88 & 1.90 \\
\hline 7. & {$[\mathrm{HeExN}]$ This boy is not healthy except for a cold } & 1.52 & 1.17 \\
\hline 8. & [HeNBa] This boy is sick & 6.92 & 0.27 \\
\hline 9. & [HeNEx] This boy is sick except for a cold & 1.48 & 0.98 \\
\hline 10. & [HeNExN] This boy is not sick except for a cold & 4.16 & 2.07 \\
\hline 11. & {$[\mathrm{NaBa}]$ This film is Italian } & 6.96 & 0.20 \\
\hline 12. & {$[\mathrm{NaBa}]$ This immigrant is Italian } & 6.92 & 0.27 \\
\hline 13. & [NaBe1s] This film is more Italian than American & 6.12 & 1.21 \\
\hline 14. & {$[\mathrm{NaBe} 2 \mathrm{~s}]$ This film is more Italian than that film is American } & 3.92 & 1.79 \\
\hline 15. & [NaCo1] This film is Italian compared to that film & 3.2 & 1.96 \\
\hline 16. & {$[\mathrm{NaCo} 2]$ This man is Italian compared to that film } & 1.92 & 1.35 \\
\hline 17. & [NaEx1] This film is Italian except with respect to the music & 4.84 & 1.99 \\
\hline 18. & [NaEx2] This immigrant is an Italian except with respect to the accent & 3.08 & 2.00 \\
\hline 19. & [NaExN1] This film is not Italian except with respect to the music & 4.52 & 2.04 \\
\hline 20. & $\begin{array}{l}\text { [NaExN2] This immigrant is not an Italian except with respect to the } \\
\text { accent }\end{array}$ & 3.48 & 2.23 \\
\hline 21. & [NaWh1] This film is more Italian than that film & 5.24 & 1.68 \\
\hline 22. & [Filba] This musician is a big fan & 5.24 & 1.86 \\
\hline
\end{tabular}


(continued)

\begin{tabular}{|c|c|c|c|}
\hline Item & Structure: basic form & Mean & $\underline{\text { Std }}$ \\
\hline 23. & [Filba] This musician is a small fan & 2.84 & 1.78 \\
\hline 24. & [Filba] This musician is a bigger fan than that musician & 4.2 & 2.14 \\
\hline 25. & [Filba] This musician is a smaller fan than that musician & 2.44 & 1.70 \\
\hline 26. & [Cob1] This banana is bent compared to that banana & 5.12 & 2.20 \\
\hline 27. & [Cob2] This rod is bent compared to that rod & 6.16 & 1.49 \\
\hline 28. & [Cob3] This bed is bent compared to that bed & 5.08 & 2.02 \\
\hline 29. & [Coba1] This creature is bald compared to that creature & 5.76 & 1.03 \\
\hline 30. & [Cobi1] This building is big compared to that building & 6.56 & 0.90 \\
\hline 31. & [Cobi2] This pencil is big compared to that pencil & 6.68 & 0.61 \\
\hline 32. & [Coch1] This dress is cheap compared to that dress & 6.84 & 0.46 \\
\hline 33. & [Coch2] This apartment is cheap compared to that apartment & 6.92 & 0.27 \\
\hline 34. & [Coe1] This tea glass is empty compared to that tea glass & 5.88 & 1.37 \\
\hline 35. & [Coe2] This wine glass is empty compared to that wine glass & 5.64 & 1.62 \\
\hline 36. & [Coe3] This espresso cup is empty compared to that espresso cup & 4.56 & 1.94 \\
\hline 37. & [Coe4] This jam jar is empty compared to that jam jar & 5.36 & 1.81 \\
\hline 38. & [Coe5] This whiskey glass is empty compared to that whiskey glass & 5.36 & 1.85 \\
\hline 39. & [Coex 1] This dress is expensive compared to that dress & 6.88 & 0.32 \\
\hline 40. & [Coex2] This apartment is expensive compared to that apartment & 6.8 & 0.40 \\
\hline 41. & [Cof1] This tea glass is full compared to that tea glass & 5.6 & 1.67 \\
\hline 42. & [Cof2] This wine glass is full compared to that wine glass & 5.92 & 1.38 \\
\hline 43. & [Cof3] This espresso cup is full compared to that espresso cup & 5.64 & 1.65 \\
\hline 44. & [Cof4] This jam jar is full compared to that jam jar & 5.72 & 1.37 \\
\hline 45. & [Cof5] This whiskey glass is full compared to that whiskey glass & 6 & 1.26 \\
\hline 46. & [Coh1] This creature is hairy compared to that creature & 6.48 & 0.81 \\
\hline 47. & [Cos1] This banana is straight compared to that banana & 5.92 & 1.57 \\
\hline 48. & [Cos2] This rod is straight compared to that rod & 6.04 & 1.56 \\
\hline 49. & [Cos3] This bed is straight compared to that bed & 5.92 & 1.32 \\
\hline 50. & [Cosh1] This girl is short compared to that girl & 6.56 & 0.80 \\
\hline 51. & $\begin{array}{l}\text { [Cosh2] This basketball player is short compared to that basketball } \\
\text { player }\end{array}$ & 6.56 & 0.94 \\
\hline 52. & [Cosm1] This building is small compared to that building & 6.8 & 0.49 \\
\hline 53. & [Cosm2] This pencil is small compared to that pencil & 6.52 & 0.90 \\
\hline 54. & [Cot1] This girl is tall compared to that girl & 6.28 & 1.28 \\
\hline 55. & [Cot2] This basketball player is tall compared to that basketball player & 6.28 & 0.87 \\
\hline 56. & [Cota1] This ice-cream is tasty compared to that ice-cream & 6.56 & 0.64 \\
\hline 57. & [Cotle1] This ice-cream is tasteless compared to that ice-cream & 6.6 & 0.89 \\
\hline
\end{tabular}




\section{References}

Baker, M. C. (2003). Lexical categories: Verbs, nouns, and adjectives. Cambridge: Cambridge University Press.

Bard, E. G., Robertson, D., \& Sorace A. (1996). Magnitude estimation of linguistic acceptability. Language, 72(1), 32-68.

Bartsch, R. (1986). Context-dependent interpretations of lexical items. In J. Groenendijk, D. de Jongh \& M. Stokhof (Eds.), Foundations of pragmatics and lexical semantics, GRASS 7 (pp. 1-26). Dordrecht: Foris.

Baayen, R. H., Davidson, D. J., \& Bates, D. M. (2006). Mixed-effects modeling with crossed random effects for subjects and items. Journal of Memory and Language, 59(4), 390-412.

Buhrmester, M., Kwang, T., \& Gosling, S. D. (2011). Amazon's mechanical turk: A new source of inexpensive, yet high-quality, data? Perspectives on Psychological Science, 6, 3-5.

Constantinescu, C. (2011). Gradability in the nominal domain. Doctoral dissertation, Rijksuniversiteit Leiden.

Davies, M. (2010). Corpus of Contemporary American English (http://corpus.byu.edu/coca). Brigham Young University.

de Vries, H. (2010). Evaluative degree modification of adjectives and nouns. Master's thesis, Utrecht Institute of Linguistics.

Espinal, M. T. (2013). Bare nominals, bare predicates: Properties and related types. In J. Kabatek \& A. Wall (Eds.), Bare noun phrases in romance: Theory and (empirical) data. Amsterdam: John Benjamins.

Fox, D., \& Hackl, M. (2006). The universal density of measurement. Linguistics and Philosophy, 29, 537-586.

Gardenfors, P. (2004). Conceptual spaces-The geometry of thought. Cambridge, Massachusetts: MIT Press.

Giannakidou, A., \& Yoon, S. (2011). The subjective mode of comparison: Metalinguistic comparatives in Greek and Korean. Natural Language \& Linguistic Theory, 29, 621-655.

Hampton, J. A., Storms, G., Simmons, C. L., \& Heussen, D. (2009). Feature integration in natural language concepts. Memory and Cognition, 37(8), 1150-1163.

Hampton, J. A. (2007). Typicality, graded membership and vagueness. Cognitive Science, 31, $355-383$.

Hampton, J. A. (1995). Testing the prototype theory of concepts. Journal of Memory and Language, 34, 686-708.

Hampton, J. A. (1998). Similarity based categorization and fuzziness of natural categories. Cognition, 65, 137-165.

Heim, I. (2000). Degree operators and scope. In Proceedings of SALT 10. Ithaca, NY: CLC Publications.

Hoeksema, J. (1995). The semantics of exception phrases. In J. van Eijck \& J. van der Does (Eds.), Quantifiers, logic, and language (pp. 145-177). Stanford: CSLI.

Kamp, H. (1975). Two theories about adjectives. In E. L. Keenan (Ed.), Formal semantics of natural language (pp. 123-155). Cambridge: Cambridge University Press.

Kennedy, C. (1999). Projecting the adjective: The syntax and semantics of gradability and comparison. New York: Garland.

Klein, E. (1980). A semantics for positive and comparative adjectives. Linguistics and Philosophy, $4(1), 1-45$.

Landman, F. (1989). Groups II. Linguistics and Philosophy, 12, 723-744.

Lasersohn, P. (1999). Pragmatic halos. Language, 75, 522-551.

McCloskey, M. E., \& Glucksberg, S. (1978). 'Natural categories: Well defined or fuzzy sets'? Memory \& Cognition, 6, 462-472.

Medin, D. L., \& Schaffer, M. M. (1978). Context theory of classification learning. Psychological Review, 85(3), 207-238. 
Moltmann, F. (1995). Exception phrases and polyadic quantification. Linguistics and Philosophy, $18,223-280$.

Morzycki, M. (2009). Degree modification of gradable nouns: Size adjectives and adnominal degree morphemes. Natural Language Semantics, 17(2), 175-203.

Morzycki, M. (2011). Metalinguistic comparison in an alternative semantics for imprecision. Natural Language Semantics, 19(1), 39-86.

Murphy, G. (2002). The big book of concepts. Cambridge, MA: The MIT Press.

Rosch, E. (1973). Natural categories. Cognitive Psychology, 4(3), 328-350.

Rosch, E., \& Mervis, C. B. (1975). Family resemblances: Studies in the internal structure of categories. Cognitive Psychology, 7, 573-605.

Roth, E., \& Shoben, E. J. (1983). The effect of context on the structure of categories. Cognitive Psychology, 15, 346-378.

Sassoon, G. W. (2012). The double nature of negative antonymy. In The Proceedings of Sinn und Bedeutung 16. Utrecht.

Sassoon, G. W. (2013a). Vagueness, gradability, and typicality, the interpretation of adjectives and nouns. Leiden: Brill.

Sassoon, G. W. (2013b). A typology of multidimensional adjectives. Journal of Semantics, 30, 335-380.

Sassoon, G. W. (2015). Between noun comparisons. In Selected papers from the 10th TbiLLC conference, Lecture notes in artifical intelligence. Springer.

Sassoon, G. W. (2014). The type of adjectives. In M. Aloni, M. Franke \& F. Roelofsen (Eds.), Proceedings of the 19th Amsterdam colloquium.

Shamir, A. (2013) Disjunctivity. Master thesis. The Hebrew University, Jerusalem.

Tversky, A. (1977). Dimensions of similarity. Psychological Review, 84, 327-352.

von Fintel, K. (1994). Restrictions on quantifier domains. Doctoral dissertation, University of Massachusetts, Amherst.

von Stechow, A. (1984). Comparing semantic theories of comparison. Journal of Semantics, 3, $1-77$.

Wattenmaker, W. D. (1995). Knowledge structures and linear separability: Integrating information in object and social categorization. Cognitive Psychology, 28, 274-328.

Open Access This chapter is licensed under the terms of the Creative Commons Attribution 4.0 International License (http://creativecommons.org/licenses/by/4.0/), which permits use, sharing, adaptation, distribution and reproduction in any medium or format, as long as you give appropriate credit to the original author(s) and the source, provide a link to the Creative Commons license and indicate if changes were made.

The images or other third party material in this chapter are included in the chapter's Creative Commons license, unless indicated otherwise in a credit line to the material. If material is not included in the chapter's Creative Commons license and your intended use is not permitted by statutory regulation or exceeds the permitted use, you will need to obtain permission directly from the copyright holder.

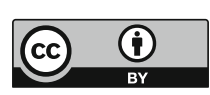

